OPEN ACCESS

Edited by:

Denise M. Mitrano,

Swiss Federal Institute of Aquatic Science and Technology, Switzerland

Reviewed by:

Veronique Adam,

Swiss Federal Laboratories

for Materials Science and Technology,

Switzerland

Yousuf Hussain Mohammed,

The University of Queensland,

Australia

*Correspondence: Jérôme Labille labille@cerege.fr

Specialty section:

This article was submitted to Biogeochemical Dynamics,

a section of the journal

Frontiers in Environmental Science

Received: 30 March 2020

Accepted: 10 June 2020

Published: 10 July 2020

Citation:

Labille J, Catalano R, Slomberg D, Motellier S, Pinsino A, Hennebert $P$, Santaella C and Bartolomei V (2020)

Assessing Sunscreen Lifecycle

to Minimize Environmental Risk Posed by Nanoparticulate UV-Filters -

A Review for Safer-by-Design

Products. Front. Environ. Sci. 8:101.

doi: 10.3389/fenvs.2020.00101

\section{Assessing Sunscreen Lifecycle to Minimize Environmental Risk Posed by Nanoparticulate UV-Filters - A Review for Safer-by-Design Products}

\author{
Jérôme Labille ${ }^{1 *}$, Riccardo Catalano', Danielle Slomberg', Sylvie Motellier², \\ Annalisa Pinsino ${ }^{3}$, Pierre Hennebert ${ }^{4}$, Catherine Santaella ${ }^{5}$ and Vincent Bartolomei ${ }^{2}$
}

\begin{abstract}
${ }^{1}$ CNRS, IRD, INRAe, Coll France, CEREGE, Aix Marseille University, Aix-en-Provence, France, ${ }^{2}$ University Grenoble Alpes, Commissariat á l'Energie Atomique et aux Energies Alternatives, DRT/LITEN/DTNM/STDC/Laboratory of Measure, Safety, and Environment, Grenoble, France, ${ }^{3}$ Istituto per la Ricerca e I'Innovazione Biomedica, Consiglio Nazionale delle Ricerche, Palermo, Italy, ${ }^{4}$ National Institute for Industrial Environment Risk (INERIS), Aix-en-Provence, France, ${ }^{5}$ Aix Marseille Univ, CEA, CNRS, BIAM, Laboratory of Microbial Ecology of the Rhizosphere, Saint-Paul-lès-Durance, France
\end{abstract}

Sunscreens are of emerging concern regarding environmental effect. After leaving the skin either through bathing or washing, the ingredients contained in the product formulation can be released into rivers, lakes, seashores, and/or sewage treatment plants. Nanomaterials used as UV-filters are of particular concern in this context as they may have a negative effect on these systems. To assess the risks posed, the exposure and hazard of nanoparticulate UV-filters must be considered through the entire lifecycle of the sunscreen product. This includes not only usage, but also manufacturing and disposal at the end of life of the product, as some nanomaterials may be released into the environment at each stage. This includes also developing relevant approaches that take into account realistic scenarios of environmental release and fate. Nanoparticulate UV-filters typically consist of a mineral nanoparticle core $\left(\mathrm{TiO}_{2}\right.$ or $\mathrm{ZnO}$ ) coated with surface layers aimed at optimizing the dispersion in the formulation and at supressing any photo-sensibility. This coating plays a key role in the associated risk since it affects the nanoparticle surface properties, which control both fate and hazard. At present, knowledge gaps remain regarding the safety of nanomaterials used in sunscreen, as very few studies have focused on real sunscreen filters and formulations throughout their lifecycle so far. A literature review is proposed here from the design of nanoparticulate UV-filters and formulations, to the release, fate, and effect in the different compartments encountered along the product lifecycle. The resulting state of the art highlights knowledge gaps and will likely help regulators, manufacturers, and consumers choose appropriate guidance. By considering each development stage of the sunscreen, from the choice of the UV-filter(s) and its (their) integration into a cosmetic 
formulation to the knowledge of the risk involved in this choice all along the product lifecycle, an eco-design approach can be achieved where release or toxicity are reduced. Sustainability can thus be accounted for, during the design process, by making the appropriate choices (in advance) that help minimize or prevent the environmental impact of the sunscreen.

Keywords: UV filter (sunscreen), nano risk, lifecycle, fate and transport model, safe by design, nanoparticle, environment pollution

\section{INTRODUCTION}

Our modern lifestyle implies frequent exposure to the sun's rays, during everyday and recreational activities. Sunscreen usage is often needed to protect our skin against the damaging effects of UV rays, that include accelerated aging and skin cancer. Sunscreen products are conceived by the cosmetic industry in a way that composition, labeling, and efficacy to block UV rays are in accordance with local regulations. Nowadays, in the context of global changes, the multiple impacts of anthropic activities on the environment are of rising concern, and the case of sunscreens has come into consideration. While their usage must remain a health priority, sunscreen composition can be formulated to minimize its effects on the environment, in relation with the ingredients they contain. Sunscreens typically consist of a complex oilin-water $(\mathrm{o} / \mathrm{w})$ or water-in-oil (w/o) emulsion in which UVfilters, the major active ingredients, are incorporated at high concentration. The UV-filters can be organic or mineral in nature, and provide the desired solar protection factor (SPF) that is labeled on the product packaging (Steinberg, 2007). Some organic UV-filters found in many sunscreens have been blamed for having endocrine disrupting capacities inducing adverse effects on fecundity and reproduction (Schlumpf et al., 2004; Kunz and Fent, 2006; Calafat et al., 2008; Bluthgen et al., 2012), as well as causing adverse effects on marine systems (Calafat et al., 2008; Danovaro et al., 2008; Kunz and Fent, 2009; Sanchez-Quiles and Tovar-Sanchez, 2014; Downs et al., 2016; Sendra et al., 2017; Fel et al., 2019; Rodriguez-Romero et al., 2019; Tovar-Sanchez et al., 2019). While mineral UVfilters may offer an alternative to synthetic organic UV-filters, their toxicity, fate, and overall impact on the environment are still under consideration, and their resulting acceptance by the consumers is largely related to the potential risks of nanotechnology-based products. Bombarded with alarmist information about nanomaterials, consumers are now wary of spreading products containing these substances on their skin, as they question the benefit-risk ratio of the product. What about the toxicity that this implies for their health and for the environment?

Nanometric titanium dioxide $\left(\mathrm{TiO}_{2}\right)$ or zinc oxide $(\mathrm{ZnO})$ UV-filters have many advantages in terms of sun protection and aesthetics and thus constitute a main active ingredient of sunscreens. However, after leaving the skin either through bathing or washing, such engineered nanomaterials (ENM) contained in the sunscreen can be released into rivers, lakes, seashores, and/or sewage treatment plants. In order to assess the related risks posed and the global environmental footprint of the product, their fate and effect in these different systems must be considered along with the product lifecycle.

Here we discuss how safe-by-design sunscreens can be developed by considering and minimizing the risk associated with ENMs at all stages of the cream lifecycle, from its manufacture to its end of life, through the consumer use and its effects on the exposed environment. In this review, the impact of sunscreen components on the consumer health via topical application and direct transcutaneous exposure is not considered, because this constitutes a priority point of consideration and evaluation for the respective country regulators and has thus been systematically studied (see e.g., Osmond and McCall, 2010; Schneider and Lim, 2019 and references therein). Here, we focus on the scientific questions regarding the environmental effects of sunscreen products, and particularly of nanoparticulate UVfilters. Key stages of the sunscreen lifecycle and the related scientific literature are developed in this review. This includes (i) the sunscreen design at both scales of UV-filter selection and formulation optimization; (ii) the aquatic environment directly exposed via bathing activity, or indirectly exposed via domestic wastewater pathways; (iii) the induced potential hazards on aquatic organisms; and (iv) the product fate at its end of life regarding management of treatment plant sludge and solid waste disposal, incineration or recycling (Figure 1). In addition, new experimental approaches are also proposed when specific questions are not yet, or not sufficiently, addressed in the scientific literature. Although there is extensive scientific literature on the nanosafety of $\mathrm{TiO}_{2}$ and $\mathrm{ZnO}$ ENMs, only a minor part of it deals with the UV filter application. In this review, we primarily focused on this minor part, including original UV filters as well as aged UV filters, to be relevant to the lifecycle stages explored. However, when no or few references could be found at any of the above-mentioned stages, our review was extended more widely to the literature on sunscreens in general or on bare nano- $\mathrm{TiO}_{2}$ and nano- $\mathrm{ZnO}$. The resulting state of the art contributes to establish an objective cost/benefit evaluation regarding the use of nanoparticulate UV-filters in sunscreen cosmetic products. It aims at helping regulators, manufacturers and consumers to follow appropriate criteria in their respective choices, while some remaining knowledge gaps are also raised. By considering each development stage of the sunscreen, from the choice of the UV-filter(s) and its (their) integration into a cosmetic formulation, to the knowledge of the risk involved in this choice all along the product lifecycle, an eco-design approach can be achieved and risk can be minimized (Figure 2). 


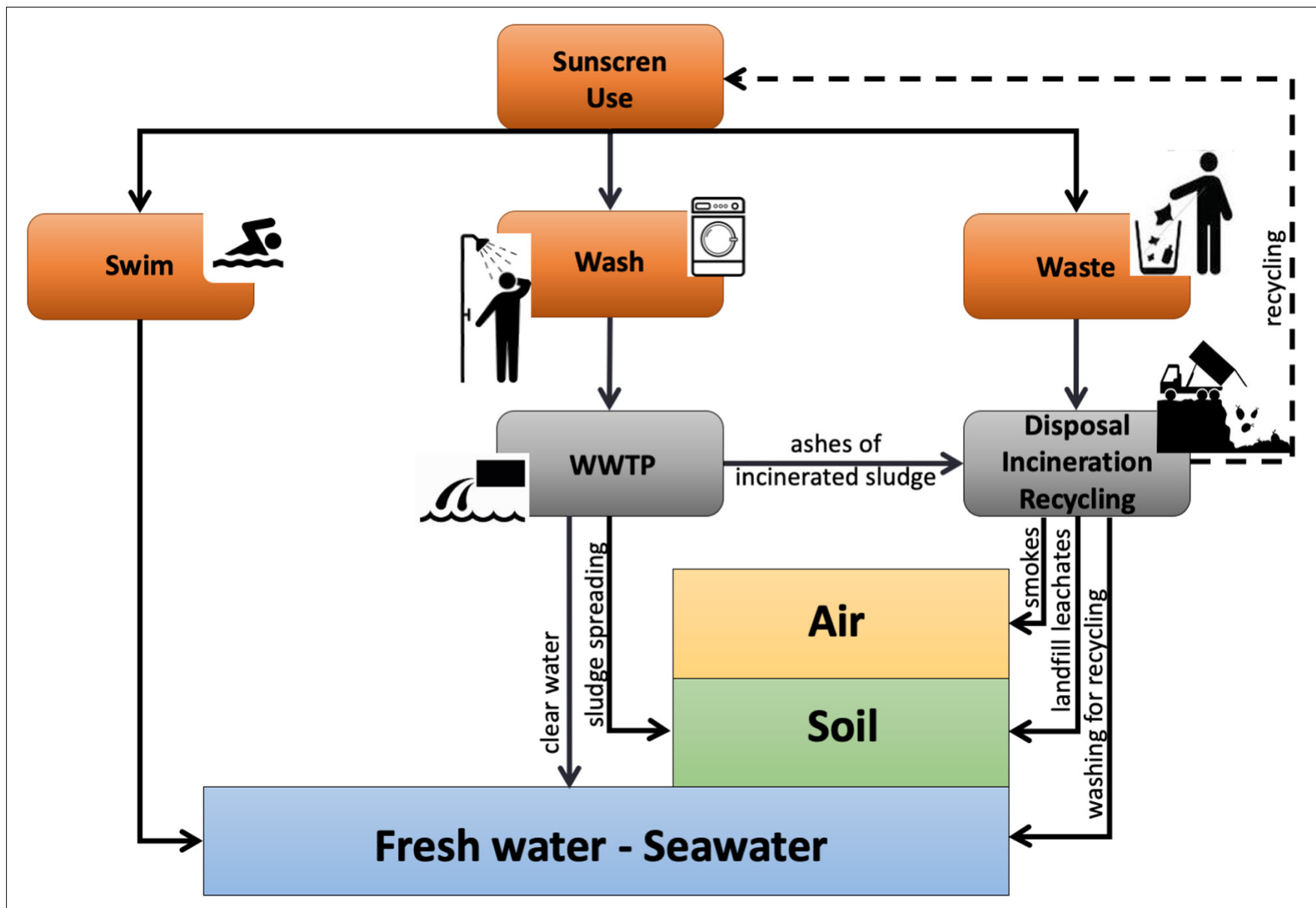

FIGURE 1 | Possible transport pathways from sunscreen use to air, water or soil, through bathing water, domestic wastewater, and solid waste disposal.

\section{SUNSCREEN DESIGN}

Environmental Life Cycle Assessment (LCA) quantifies the environmental impacts associated with a good or service throughout its lifecycle, from raw material extraction, manufacturing, distribution and use, to final recycling and waste disposal. In the cosmetics industry, LCA and other life cycle thinking approaches such as Environmental-, Carbonand Water-footprinting have been used to identify and measure environmental impacts and prioritize adaptations to products, processes and packaging to develop cosmetics with improved environmental profiles (Cosmetics Europe TPCA, 2018). The development of formulations with a smaller carbon footprint or with a higher share of readily biodegradable raw materials is promoted so that the eco-design of formulas and packaging are encouraged via education and sharing of best practices. Sustainability can be accounted for during the design process by making the appropriate decisions in advance to minimize the environmental risk posed by the sunscreen ingredients (Figure 2). For example, reducing the potential release and/or (eco)toxicity of the nanoparticles contained in the cream during its entire lifecycle is a decisive criterion for its eco-design. Both the active UV-filter(s) and the emulsion type in which it (they) is (are) incorporated are to be considered. The surface properties of the former and the overall characteristics of the latter both control the potential ecological impact of the sunscreen along its lifecycle.

\section{UV-Filter Selection}

$\mathrm{ZnO}$ and $\mathrm{TiO}_{2}$ are both used in sunscreens as mineral UVfilters as they are able to reflect and absorb UV-rays. ZnO has a broad UVA- UVB absorption curve, while $\mathrm{TiO}_{2}$ provides better UVB absorption and a UVA protection depending on the particle size (Smijs and Pavel, 2011; Schneider and Lim, 2019). This is because in this range of $320-400 \mathrm{~nm}$, UV-rays are rather scattered by nano- $\mathrm{TiO}_{2}$ (Shao and Schlossman, 1999) and optimal scattering is thought to occur when the diameter of the particles is approximately half the wavelength of the light to be scattered (Fairhurst and Mitchnick, 1997; U.S. EPA, 2010). When used together, $\mathrm{ZnO}$ and $\mathrm{TiO}_{2}$ provide a good broadband UV protection. These mineral UV-filters typically consist of a $\mathrm{ZnO}$ or $\mathrm{TiO}_{2}$ nanoparticulate core with size varying from tens to hundreds of $\mathrm{nm}$. Different combinations of coating obtained by different routes of surface functionalization aim at blocking the nanomaterial photoactivity and favor dispersion of the nanomaterial in the sunscreen formulation. 


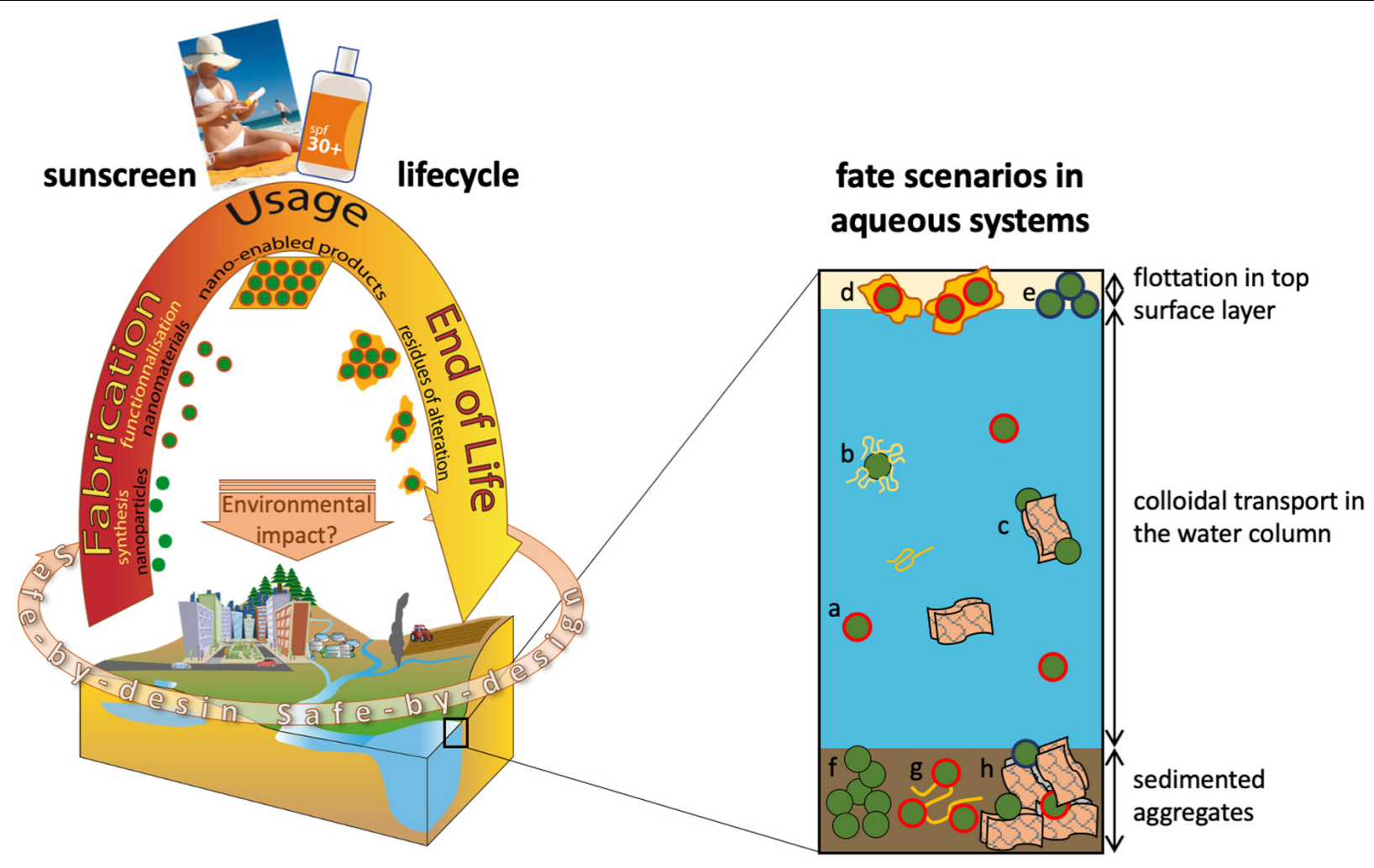

FIGURE 2 | Integrating the entire lifecycle of the sunscreen product from fabrication to end of life enables to anticipate the environmental release and impact of the involved ENMs, and tune the product in a safe-by-design approach to minimize the risk posed. Possible aqueous fate scenarios include (i) stabilization in suspension in the presence of a hydrophilic coating (e.g., $\mathrm{SiO}_{2}$, polyacrylate) (a), of natural organic matter adsorbing on the ENM (b), or of natural particulate matter vectorising the ENM (c); (ii) flotation in the water top surface layer if the ENM is embedded in hydrophobic sunscreen ingredients (d), or coated with a hydrophobic layer (e.g., dimethicone, stearic acid) (e); (iii) sedimentation following aggregation due to homoaggregation (f), bridging flocculation (g), or heteroaggregation (h).

\section{UV-Filter Photopassivation}

The efficient absorption of UV wavelengths by $\mathrm{ZnO}$ or $\mathrm{TiO}_{2}$ is enabled via the excitation of the outermost electrons of the constituting atoms. However, this comes with the generation of reactive oxygen species (ROS) when the electrons come back to a stable state. In particular, photo-induced reactions of $\mathrm{TiO}_{2}$ have gained much attention and have proved to be useful in environmental applications like wastewater treatment processes (Herrera Melian et al., 2000). This so-called photocatalytic feature has to be eliminated in sunscreen products in order to prevent any induced oxidative stress on the skin or damage of the lotion (Wakefield et al., 2004; Sendra et al., 2017). For this reason, the less photocatalytic rutile form of $\mathrm{TiO}_{2}$ is preferred to the anatase form in cosmetic applications (Fujishima et al., 2008). In addition to high material purity, photopassivation is a priority criterion to authorize any $\mathrm{TiO}_{2}$ candidate to the role of UVfilter in cosmetic products. Of note, the European Scientific Committee on Consumer Safety (SCCS) adopted a threshold of photopassivation efficiency (no more than $10 \%$ of pure $\mathrm{TiO}_{2}$ rutile) to accept any $\mathrm{TiO}_{2}$ nanomaterial candidates for sunscreen use (SCCS, 2014). Generally, $\mathrm{TiO}_{2}$ photopassivation is achieved by precipitating an inert mineral layer at the nanoparticle surface. The most common photopassivating coatings found in sunscreen are alumina and silica (Braun et al., 1992; King et al., 2008;
Labille et al., 2010). Another approach proposed to increase $\mathrm{TiO}_{2}$ nanoparticles photostability, consists in "doping" the particle with metals such as manganese, vanadium, chromium, and iron (Wakefield et al., 2004). Manganese for example, occupies some titanium sites in the nanoparticle lattice structure, where it creates a electron-hole de-excitation route, giving the sunscreen the advantages of increased UV-A absorption, reduced free radical generation, and increased free radical scavenging behavior.

\section{UV-Filter Dispersion in the Formulation}

The ability to prepare and handle concentrated and stable dispersions of nanoparticles is important for the performance of the final product since aggregation is a major cause of poor performance in UV ray absorption and of limited transparency. Efficient utilization of the broad absorption in the UV-B and UV-A regions of mineral UV-filters in transparent sunscreens requires not only that the particle size be reduced far below the wavelength of visible light but also that dispersion be maximized (Tyner et al., 2011; Faure et al., 2013). If such conditions are fulfilled, it takes a significantly lower concentration of finely dispersed nanoparticles in the formulated product than needed with large aggregates to attain the same functionality, i.e., a given solar protection factor. This reduced metal "load" in the final product is also an interesting point in lowering environmental 
exposure. This is evidenced in Figure $\mathbf{3 A}$, plotting the UV absorption of different commercial nanoparticulate $\mathrm{TiO}_{2}$ UVfilters dispersed in a sunscreen oil, as a function of the aggregate size. This relation is due to the sunscreen homogeneity that is maximized when the UV-filter aggregate size is minimized, as highlighted by 2D X-ray nano-tomography (Figure 3B) for two contrasting formulations (Catalano, 2020). The lower sunscreen image evidences the existence of large aggregates forming overconcentrated patches of several $\mu \mathrm{m}$ size that caused a lower UV absorption efficacy. Meanwhile, no significant difference was observed between the respective UV-filters at the $\mathrm{nm}$ scale of the primary particle, because both consisted of ultrafine rutile nanoparticles (Figure 3C).

This determining role is given to the outermost nanoparticle coating. Organic additives are grafted to the inorganic surface to improve the compatibility with the dispersing medium and thus favor the nanoparticle dispersion in the cream (Catalano et al., 2020). A hydrophilic, amphiphilic or lipophilic feature is given to the nanoparticles via this coating process, in order to preferentially enhance their dispersion in the aqueous or the oil phase of the emulsion (Faure et al., 2013). For example, silane-type polymers such as poly-dimethylsyloxane or stearic acid result in a lipophilic surface character (Labille et al., 2010), while polyacrylic acid or bare silica coating typically favor aqueous dispersion (Dzumedzey et al., 2017; Rowenczyk et al., 2017). Amphiphilic character can also be obtained with, e.g., simethicone coating, which enables nanoparticle dispersion in both oil and water phases (Schulz et al., 2002; Faure et al., 2013).

From an industrial point of view, an optimal UV filter formulation is generally sought indirectly by maximizing the SPF and shelf life while minimizing the dosage of the active ingredients. However, in a mechanistic approach, any attempt to optimize the ENM dispersion in the sunscreen formulation has to deal with the analytical challenge of the cream characterization. Generally, this involves ENM extraction based on dispersion of the material in a surfactant solution or a solvent phase, sonication, and ultracentrifugation or ultrafiltration (Contado and Pagnoni, 2010; Dan et al., 2015; Philippe et al., 2018). Philippe et al. (2018) have pointed out the challenge of this extraction process with respect to the agglomeration state of the ENMs. In their screening of 11 commercialized sunscreens, while cryoTEM revealed that most of the particles were agglomerated in the creams/lotions, the "mild" extraction methods proposed resulted in dispersed primary particles, questioning the representativeness and relevancy of such extracted particles for environmental and toxicology studies. Some dense micro-aggregates most often exist with $\mathrm{TiO}_{2}$ nanoparticles, which result from the synthesis process. They are due to secondary precipitation at the contact points between the primary particles, binding them together into a larger assembly. A key question regarding safety is whether such aggregates remain intact throughout the entire sunscreen

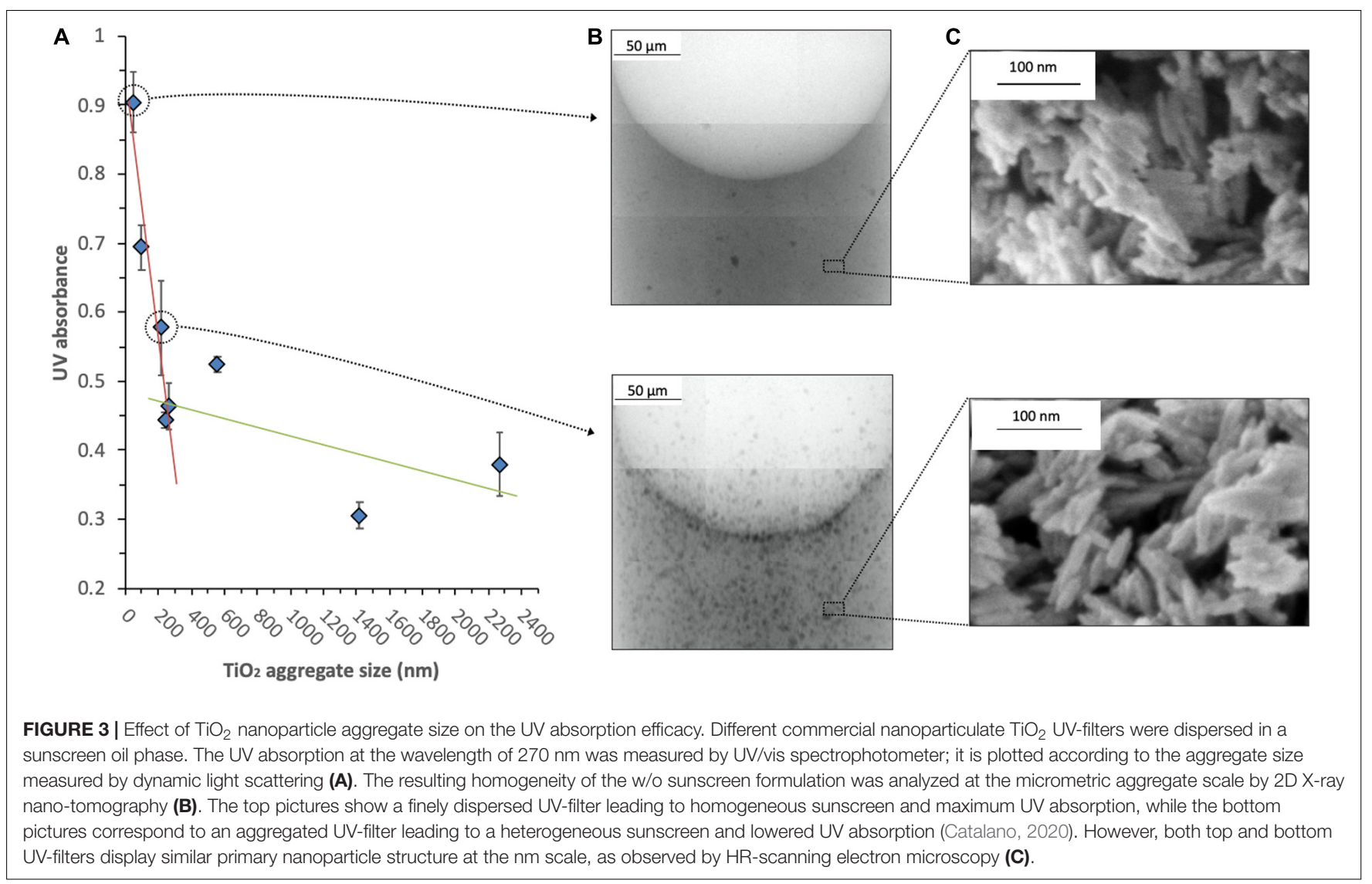


lifecycle, because the size of the smallest dispersed units will certainly affect the environmental risk associated both in terms of exposure and hazard. Indeed, decreasing the size of nanoparticles down to that of primary particles around $20 \mathrm{~nm}$ may favor bioaccessibility and internalization by living organisms and transfer via the food chain. Nevertheless, it is worthwhile noting that for precautionary principle, the EU cosmetic regulation 1223/2009 considers the smallest existing units (Eur-Lex, 2009). According to this regulation, the definition of a nanomaterial below the size threshold of $100 \mathrm{~nm}$ is based either on the external dimensions or on the internal structure of that material. The internal structure of the material prevails on the outer size of some possibly existing aggregates because the fragmentation of such aggregates along the product lifecycle and the resulting dispersive potential of the ENMs are mostly unknown.

The chemical coating of the nanoparticle surface thus plays a determining role at many stages of the sunscreen lifecycle and should be optimized at the manufacturing stage in an ecodesign concept. At the conception and production stages, it must both increase UV absorption efficiency by maximizing the particle dispersion in the formulation matrix and optimize the photopassivation of the functional nanoparticle core, while during further stages like usage and end of life of the sunscreen, this coating may determine both the nanomaterial fate and toxicity in the environment (see sections "Release, fate and exposure in aquatic systems" and "Effects on aquatic living organisms").

\section{Effects of the Formulation Ingredients on the ENM Fate}

Different types of formulations are used on sunscreen market, mostly constituted of either water-in-oil (w/o) or oil-in-water $(\mathrm{o} / \mathrm{w})$ emulsions, one or the other type being preferred to tailor the rheology and to obtain specific galenic properties. The nanoparticulate UV-filters can be dispersed in one or the other liquid phase of the emulsion (Semenzato et al., 1994; Turkoglu and Yener, 1997; Gamer et al., 2006; MonteiroRiviere et al., 2011; Tyner et al., 2011; Faure et al., 2013). In addition, sunscreen formulations usually contain emulsifying, thickening and preservative agents all aimed at maximizing the stability of the final product. All these ingredients mixed together result in a complex system in which cross effects may take place. Some formulation ingredients can unintentionally interact with the nanoparticulate UV-filters and alter their properties (Rossano et al., 2014). For example, Catalano et al. (2020) found that an emulsifying agent containing a glucosidic moiety can adsorb onto the nanoparticulate UV-filter and alter its dispersion, finally affecting the UV absorption of the sunscreen (Figure 3). A mixture effect exists and must be considered and optimized in a safe-by-design approach, not only at the fabrication stage of product quality control, but also at further lifecycle stages because certain ingredient combinations affect weathering and environmental dispersion of the product (Botta et al., 2011; Tovar-Sanchez et al., 2019). In this context, the expected contrasted fates of the oily or aqueous by-products are of particular interest in future research.

\section{RELEASE, FATE AND EXPOSURE IN AQUATIC SYSTEMS}

Sunscreens can be washed off the skin either through bathing activity or via a domestic wastewater pathway. The formulations and their ingredients undergo a constant aging once released into aquatic media. The fate of nanoparticulate UV-filters depends on the extent and routes of the aging process and determines their potential effects on the environment. The propensity of the products to be dispersed in the aqueous phase as nanoparticles or colloids is a point that eco-design should seek to minimize.

Determining the environmental concentration of engineered nanoparticles is a challenging task that can be approached by field sampling at local scale or model estimation at varying scales. While the field approach was limited by ever evolving detection methods (see section "Environmental occurrence of UV-filters due to bathing activity") (Zhang et al., 2019), model estimations have been developed to estimate the environmental fate scenario and occurrence of ENMs in aqueous media. Even if many knowledge gaps (e.g., on ENM production, application and release) still affect the modeled values, an order of magnitude of the environmental concentrations was reached and agreed. Boxall et al. (2007) presented the first quantitative approach, predicting concentrations of various ENMs from cosmetic products in soil, sludge, and water. They obtained ranges of $24-245 \mu \mathrm{g} / \mathrm{L}$ and $76-760 \mu \mathrm{g} / \mathrm{L}$ for $\mathrm{TiO}_{2}$ and $\mathrm{ZnO}$ in water, respectively. Gottschalk et al. (2010) developed a probabilistic method to compute the distributions of environmental concentrations (PEC) in nanomaterials based on flow modeling and MonteCarlo simulation, in order to deal with the uncertainty in the model parameterization related to lack of knowledge on transfer, partitioning coefficients and emission factors. The modeled PEC values proposed in the literature are not always comparable due to the different scenarios considered and nanoparticle characteristics used. A dozen of those existing models was reviewed in 2013 in order to clarify those key parameters that determine the modeled values (Gottschalk et al., 2013).

Keller et al. (2014) estimated the ENM release from personal care products (PCP) into soils, water, air, and landfills in California and China. They accomplished this by surveying consumer's habits and analyzing container sizes and ENM concentration in each product. The total sunscreen consumption in the United States was estimated at 90,000 metric tons per year, involving 2,300-2,700 mt/yr of ENMs. Authors revealed that sunscreen is the most intensive ENM application among PCPs, with $81-82 \%$ of the total ENM mass flow, and that $\mathrm{ZnO}$ and $\mathrm{TiO}_{2}$ are the most commonly used ENMs, representing together $94 \mathrm{w} \%$ of the ENM use in PCPs. From the overall sunscreen usage, including everyday use and recreational activities, they predicted that the amount of sunscreen directly released from the skin to the bathing area water levels at $5 \%$. The rest of the consumed products was mostly used out of recreational activity, giving about $60-90 \%$ washed off during showering and flowed to the wastewater treatment plant (WWTP). The efficiency of the WWTP for ENM removal from the wastewater controls the ENM partitioning between the downstream compartments soil 
and surface water (Figure 2) (see also section "Risk related to indirect release at the product end of life").

\section{Environmental Occurrence of UV-Filters Due to Bathing Activity}

The scenario of direct release into rivers, lakes or seashores during recreational activity is of particular interest since UVfilters have been repeatedly blamed for harmful effects toward aquatic ecosystems, and particularly in coral reef areas (see section "Biological effects on marine organisms"). Indeed, as coastal tourism has reached its peak in recent decades, the use and consequently the emission of sunscreen products in the nearshore environment has increased (UNEP, 2009). A retention factor of the sunscreen on the consumer's skin needs to be determined to estimate how much of the sunscreen remains on the skin after bathing and will eventually end up in the shower outflow. This retention factor is expected to be related to the water resistance of the product, which is a point that manufacturers often try to maximize. A retention factor was measured using pig skin (a proxy for human skin) covered with five different commercial sunscreens (Jeon et al., 2016). The tested products contained $\mathrm{TiO}_{2}, \mathrm{ZnO}$, or both at various concentrations. After 30 min agitation in a synthetic swimming pool water, the release from the skin ranged from 2 to $30 \%$, and it increased to $10-$ $50 \%$ after $120 \mathrm{~min}$. A similar value of $25 \%$ was obtained with organic UV-filters released from skin to seawater after $20 \mathrm{~min}$ of immersion (Danovaro et al., 2008). From this value the authors could determine that 4,000-6,000 t/y of sunscreen are released worldwide in reef areas. At a local scale, a social survey carried out on three beaches of the Mediterranean coast enabled to estimate that on a beach attended by 3,000 people during the summer peak of activity (from June to September), an average mass of $52 \mathrm{~kg} /$ day or $1.4 \mathrm{t} / \mathrm{month}$ of suncare products is consumed before bathing (Labille et al., 2020). From these products, a mass concentration of $3-10 \%$ was reasonably used to estimate the amount of each UV-filter indicated among the component list on the packaging, giving $15.7 \mathrm{~kg}$ of UV-filter per day in average. A retention factor remains to be applied to this value to estimate the UV-filter mass possibly released to bath water. Organic UV-filters were present in most of the products consumed. As for mineral UVfilters, they were used in only $20 \%$ of the products, with $65 \%$ being labeled [nano].

The detection of anthropogenic $\mathrm{TiO}_{2}$ and $\mathrm{ZnO}$ minerals (nano or non-nano) in aquatic environments where both $\mathrm{Ti}$ and $\mathrm{Zn}$ elements naturally occur in varying background concentrations remains an analytical challenge. The available analytical methods are often not sensitive enough for current environmentally relevant concentrations and cannot distinguish natural materials in the nanoscale size range from manufactured nanomaterials (Englert, 2007; Domingos et al., 2009; Simonet and Valcarcel, 2009). Single particle (sp) ICP-MS is of particular interest in this context as it enables to detect and quantify Ti-containing particles of nanometric size at $\mathrm{ppb} / \mathrm{ppt}$ levels in a complex liquid medium (Gondikas et al., 2014, 2018; Venkatesan et al., 2018). However, high resolution equipment may sometimes be required to solve isobaric interferences, such as ${ }^{48} \mathrm{Ca}$ with regard to ${ }^{48} \mathrm{Ti}$, which can hamper the detection of titanium ENMs in waters containing high Ca concentrations, like river waters for instance (Tharaud et al., 2017). ${ }^{47} \mathrm{Ti}$ isotope may also be used but leads with a higher limit of detection due to its lower abundance. Some element ratios have been tested as proxies to distinguish the geogenic materials containing Ti or Zn elements from the ENMs in water. Indeed, any chemical element that is characteristic of geogenic materials only can be quantified relatively to the Ti or $\mathrm{Zn}$ element in order to distinguish $\mathrm{Ti}$ and $\mathrm{Zn}$ contributions due to geogenic materials from those related to ENM peak release. $\mathrm{Al}$ and $\mathrm{Si}$ are not good candidates for this purpose as they are abundant in both natural systems and in the coating of mineral UV-filters. Fe, $\mathrm{V}$ or rare earths elements (Ga, Y, Nb, Eu, Ho, Er, Tm, Yb, Ta) have been proposed as proxies for geogenic materials (Gondikas et al., 2014, 2018; Reed et al., 2017; Labille et al., 2020).

In seawater, a specific fate scenario has been observed, that facilitates the identification of mineral UV-filters: they appear concentrated in the water top surface layer (TovarSanchez et al., 2013; Labille et al., 2020) (Figures 2d,e). This preferred localization minimizes possible confusion with any geogenic material containing $\mathrm{Ti}$ or $\mathrm{Zn}$ elements since these are rather found in the water column or in sediments. This is certainly related to the hydrophobic character of some sunscreen components. Meanwhile, such vertical differentiation has not been reported yet in freshwater systems. This may be due to the high salinity of seawater that decreases the solubility of the sunscreen components. A similar effect, so-called saltingout, is known for example on protein solubility in electrolyte with very high ionic strength (Duong-Ly and Gabelli, 2014). In beaches of the Mediterranean Coast, the enrichment in UVfilters in the water top 1-cm surface layer of the bathing zone was evidenced with regard to the water column below (Labille et al., 2020), giving respectively $100-900$ and $20-50 \mu \mathrm{g} / \mathrm{L}$ of $\mathrm{TiO}_{2}, 10-15$ and $1-3 \mu \mathrm{g} / \mathrm{L}$ of $\mathrm{ZnO}$. Values corresponding to La Lave Beach are reported in Figure 4. They show similar patterns for $\mathrm{TiO}_{2}$ and $\mathrm{ZnO}$, both found in the bathing zone and preferentially concentrated in the top surface layer compared to the water column. Moreover, a tenfold concentration of $\mathrm{TiO}_{2}$ was measured with regard to $\mathrm{ZnO}$. This difference could be due to the prevalence of $\mathrm{TiO}_{2}$ over $\mathrm{ZnO}$ as a UV filter in the sunscreens consumed in Europe (Euromonitor International, 2015). Moreover, $\mathrm{ZnO}$ has a higher solubility than $\mathrm{TiO}_{2}$, which likely favors its rapid dissociation into dissolved zinc species, and thus its disappearance from the particulate fraction analyzed here. Of note, most of the UV-filters evidenced in suspension in the water column were found in a size fraction larger than $0.5 \mu \mathrm{m}$, meaning that the ENMs were not dispersed back to their initial size $<100 \mathrm{~nm}$ so far.

Both mineral and organic UV-filters can be released simultaneously in the bathing water since they are often associated in sunscreens or they originate from different products used at the same place. Consequently, they may be found together in the aquatic environment. The co-evolution of organic and mineral UV-filters has been measured in waters impacted by recreational areas with time-dependent concentrations (Tovar-Sanchez et al., 2013; Reed et al., 2017). For example, in nearshore waters of the Mediterranean coast, benzophenone 


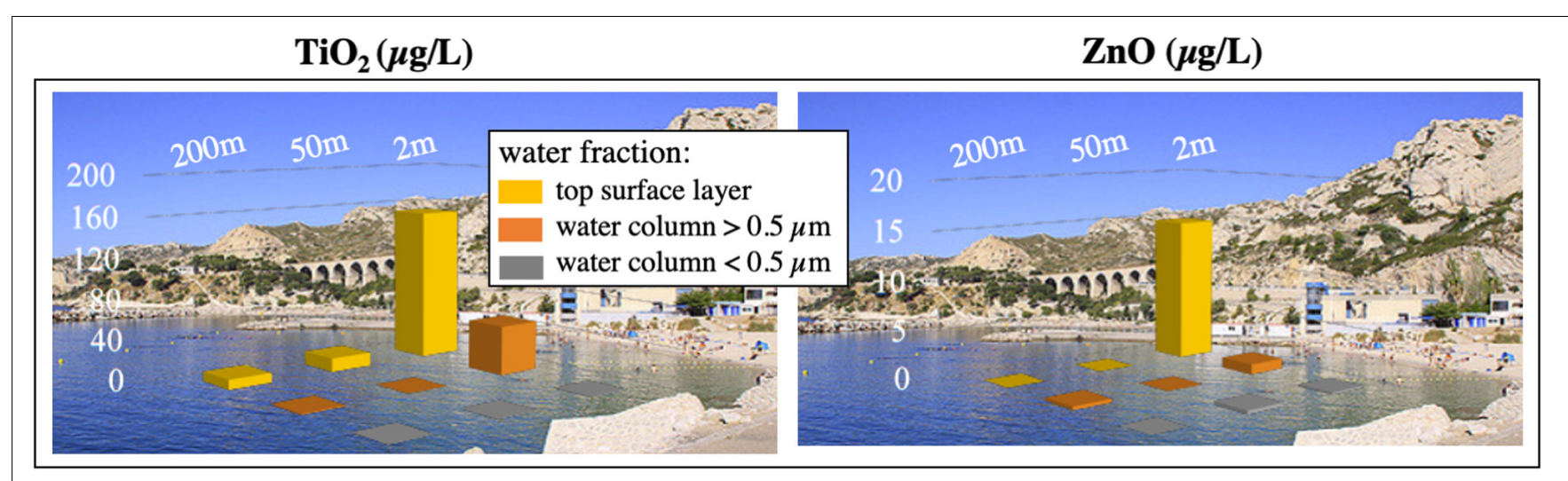

FIGURE 4 | $\mathrm{TiO}_{2}$ and $\mathrm{ZnO}$ concentrations calculated from Ti and $\mathrm{Zn}$ elements measurements in marine beach water on the French Mediterranean Coast (La Lave Beach, Marseille), at different distances from the shore line, respectively 2 and $50 \mathrm{~m}$ in the bathing zone, and $200 \mathrm{~m}$ beyond the bathing zone. Top surface layer and water column were compared. Water column samples were further fractionated by tangential flow filtration in two size classes, $>0.5 \mu \mathrm{m}$ and $0.02-0.5 \mu \mathrm{m}$, in order to estimate the aggregation state of the UV-filters (Labille et al., 2020).

3 (53.6-577.5 ng/L), 4-methylbenzylidene camphor (51.4$113.4 \mathrm{ng} / \mathrm{L})$, $\mathrm{Ti}\left(6.9-37.6 \mu \mathrm{g} / \mathrm{L}\right.$ ) (assumed related to $\mathrm{TiO}_{2}$ ), and $\mathrm{Zn}(1.0-3.3 \mu \mathrm{g} / \mathrm{L})$ (assumed related to $\mathrm{ZnO}$ ) were detected with variable concentrations along the day and mainly concentrated in the surface microlayer (Tovar-Sanchez et al., 2013). In freshwater from Colorado, oxybenzone and $\mathrm{TiO}_{2}$ were also detected together during recreation time (Reed et al., 2017). However, a lack of knowledge remains regarding the respective environmental fate and persistence of these two types of UV-filters, which may be contrasted. The hydrophilic or hydrophobic feature of the UV-filter will affect its propensity to remain individually in the water column, to float at the surface or to attach to the surface of naturally occurring suspended matter (Giokas et al., 2007) (Figure 2). In addition, the fate of particulate mineral UVfilters depends on both their solubility and their tendency to disperse or aggregate (Labille and Brant, 2010). A comparative co-evolution of both UV-filter types was proposed by Labille et al. (2020), estimating the respective fluxes from the beachgoer's skin to the bathing water. They showed that very contrasting fates exist, with $35-50 \%$ of the nanoparticulate UV-filters being recovered in water, while the organic filters were minimally recovered in the environment, most likely due to internalization through the skin barrier (Matta et al., 2019, 2020), or partial photodegradation. For this reason, it is not recommended that the organic molecules, being more easily analyzed because not present in natural background, are used as a proxy of the mineral UV-filters for environmental quantification.

\section{Mechanisms Driving the Environmental Fate}

The residence time and fate of the ENM residues in the water column is a key variable for estimating the level and duration of organism exposure in the different aqueous compartments. Strong experience was gained from past research on bare nanoparticles. The ever-existing balance between colloidal stability favoring transport in suspension and aggregation favoring rapid sedimentation and immobilization must be evaluated (Labille and Brant, 2010). Homoaggregation of ENMs may be determining when they are locally concentrated at the $\mathrm{mg} / \mathrm{L}$ level, for example close to the point of release. However, in most cases, the released ENMs are below the $\mu \mathrm{g} / \mathrm{L}$ level in surface or seawater. Then, heteroaggregation with natural inorganic or organic colloids suspended in the medium is expected to drive the ENM fate (Figure 2) (Praetorius et al., 2014; Labille et al., 2015; Sani-Kast et al., 2015).

The mechanisms driving the environmental fate of ENMs are largely determined by the nanoparticle surface properties and the medium characteristics. In the balance of forces acting at the solid/liquid interface, $\mathrm{pH}$ and ionic composition of the solution generally control the extent of particle surface charge, i.e., of electrostatic interactions with neighboring components. For example, a positive correlation was found between the aggregation rate of $\mathrm{TiO}_{2}$ ENMs and the concentration of $\mathrm{Ca}^{2+}$ in natural surface waters (Topuz et al., 2015). Dissolved organic carbon, especially high molecular weight molecules, also plays a determining role in the stabilization or agglomeration of the ENMs, depending on both the natural organic matter (NOM) nature and concentration. While NOM stabilization is usually observed (Domingos et al., 2009), bridging flocculation can be favored at low natural macromolecule concentration (Labille et al., 2010).

In addition to these well-known mechanisms on bare ENMs, a particular attention must be paid to the more or less hydrophobic character of the sunscreen and its by-products which is expected to play a role in the localization and kinetics of dispersion. This hydrophobic/philic property depends on the type of emulsion used for the product formulation. O/W emulsions are expected to readily disperse in aqueous environment since water is already the dispersing phase in the original product, whereas $\mathrm{W} / \mathrm{O}$ emulsions that display a more hydrophobic character may result in a higher water resistance of the product on the skin and a higher tendency to flotation once released (Leroy and Deschamps, 1986). Actually, both hydrophilic and hydrophobic 
scenarios may not be very distinct for a given sunscreen, as the formulation ingredients can fractionate once released in the aqueous system, depending on their respective polarities and affinities (Tovar-Sanchez et al., 2019) (Figure 2).

In ENM UV-filters, this property is typically determined by the external coating, which can be either hydrophilic or hydrophobic (see section "Sunscreen design") and will accordingly control the overall fate of the ENM. This also depends on the lifetime of the coating, which undergoes constant aging likely or not to promote the dispersion of the ENMs (Labille et al., 2010; Rossano et al., 2014). For this reason, the nature and lifetime of a given UVfilter coating must be particularly studied as a function of the environmental system encountered in order to estimate the fate scenario. Water chemistry strongly influences the aging reaction and kinetics. For example, a nano- $\mathrm{TiO}_{2} \mathrm{UV}$-filter coated with a first layer of $\mathrm{Al}(\mathrm{OH})_{3}$ and a second layer of polydymethylsiloxane (PDMS) was studied. In swimming pool water, an increase in chlorine concentration was shown to significantly affect the integrity of the $\mathrm{Al}(\mathrm{OH})_{3}$ protective layer, rendering the $\mathrm{TiO}_{2}$ nanoparticles rather unstable in suspension due to the new surface charge (Virkutyte et al., 2012). A redistribution of the $\mathrm{Al}$ atoms at the ENM surface from $\sim 4$ to as high as $15.6 \%$ was achieved when the sunscreen was subjected to 3.5 and $7 \mathrm{ppm}$ of chlorine. In a model pure water, no alteration of this $\mathrm{Al}(\mathrm{OH})_{3}$ layer was evidenced, but the integrity of the PDMS layer was shown to be strongly affected, due to the oxidation and desorption of silane moieties (Auffan et al., 2010; Labille et al., 2010). This resulted in the loss of the hydrophobic character of the aged ENMs, which favored subsequent dispersion and transport in aqueous media (Figure 5). The aging of another nano- $\mathrm{TiO}_{2}$ UV-filter coated with one single layer of $\mathrm{SiO}_{2}$ was also studied in different water chemistries. The rapid dissolution of the silica in fresh water and in seawater was evidenced by the appearance of the underlying $\mathrm{TiO}_{2}$ chemistry at the surface (Slomberg et al., 2020). This process not only decreased the colloidal stability of the aged ENMs in water, but it also implied new chemical reactivity and photoactivity. Indeed, the coating lifetime also determines how long the nanoparticles remain inert once released in the environment.

Nano-ZnO UV filters can also have surface coatings similar to those of nano- $\mathrm{TiO}_{2}$. For example, PDMS-coated nano- $\mathrm{ZnO}$ displayed a hydrophobic nature while non-coated $\mathrm{ZnO}$ easily dispersed in water (Hanigan et al., 2018). In that work, little or no PDMS dissolution was assumed after product use. Aging of the nanoparticulate UV-filter coating may also be accelerated under solar radiation, which is particularly strong when sunscreen residues tend to float at the water surface. Few data exist in the literature regarding the effect of solar radiation on the aging of mineral sunscreens or UV-filters. The $\mathrm{Al}(\mathrm{OH})_{3} / \mathrm{PDMS}$-coated nano- $\mathrm{TiO}_{2}$ mentioned here before was submitted to aging under simulated sunlight and showed an accelerated oxidation of the PDMS coating (Auffan et al., 2010). This reaction induced by sun radiation could be further controlled and studied using a climatic chamber to mimic sun radiation $\left(1.44 \mathrm{~W} \mathrm{~m}^{-2}\right.$ at $\left.420 \mathrm{~nm}\right)$, relative humidity $(50 \%)$ and temperature $\left(40^{\circ} \mathrm{C}\right)$ typical of a hot summer day on the beach. A nanoparticulate UV-filter or a real sunscreen product can be deposited on an inert substrate (e.g., PTFE) and left to age under the conditions listed above during

\section{A original ENM hydrophobic}
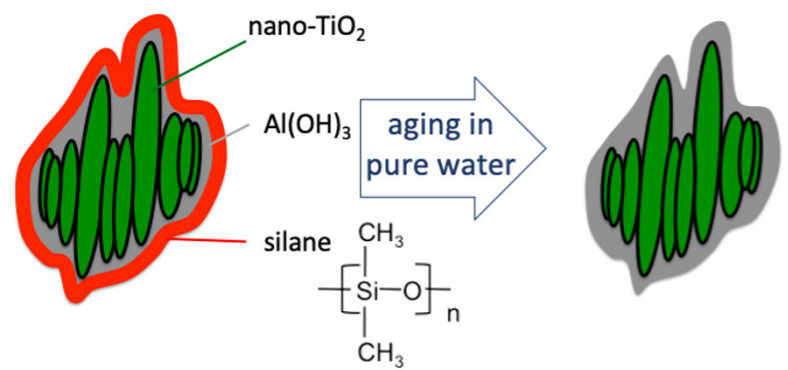

B

$$
\text { dissolved Si released in solution }
$$

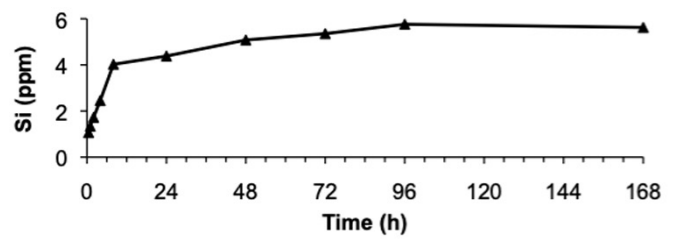
hydrophilic
C aged ENM

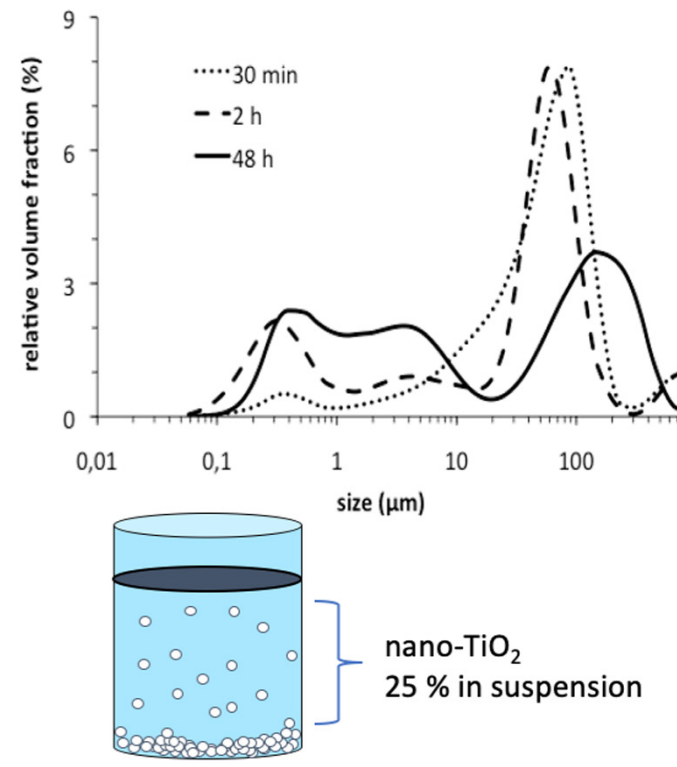

FIGURE 5 | Aging of a hydrophobic $\mathrm{TiO}_{2}$ ENM coated with $\mathrm{Al}(\mathrm{OH})_{3} / \mathrm{PDMS}$ in pure water (A). The polydimethylsiloxane (PDMS) coating alteration is confirmed by dissolved Si release (B) and leads to aqueous dispersion and colloidal stabilization (C) due to new hydrophilic Al(OH) 3 surface (Labille et al., 2010). 
a relevant time period, typically up to $8 \mathrm{~h}$ to mimic the duration of daylight. Any alteration of the nanoparticle coating induced by these conditions, could be evaluated by characterizing the physical-chemical properties of the ENM before and after aging, using spectroscopic analysis and surface charge measurement. While, such an aging scenario has not been explored for mineral UV filters to our knowledge, UV radiation is already known to alter the integrity of the polymer coating. For example, the photochemical modification of a PDMS polymer under UV irradiation was studied by Graubner et al. (2004). The authors were able to evidence the oxidation of the surface silane groups to the silanol form, such as found in the $\mathrm{SiO}_{2}$ structure, which was responsible for an increased hydrophilicity. As for stearic acid, while its photocatalytic degradation is well-known, it is assumed to be very stable under UV illumination in the absence of a photocatalyst material. For this reason, it has been widely used as a degrading probe to assess the activity of self-cleaning titania photocatalysts (Mills and Wang, 2006).

\section{EFFECTS ON AQUATIC LIVING ORGANISMS}

Whether the aged ENMs end up suspended in the water column, sedimented, or floating at the surface determines the type of environmental media and living organisms most impacted by these substances. While transport in the colloidal form comes with a large dilution of the substances and a possible exposure to planktonic organisms, sedimentation and in situ accumulation of the UV-filters imply higher local concentration and exposure to benthic organisms. Last but not least, the floating tendency of the aged UV-filters that leads to an oily film at the water surface constitutes a way of exposure to aquatic organisms that has not been studied to date, and from which the possible ecological effects remain mostly unknown.

\section{Biological Effects on Marine Organisms}

Sunscreen products are a significant source of organic and inorganic chemicals that reach the sea with potential ecological consequences on the coastal marine ecosystem. The need to understand the ecotoxicological effects on marine ecosystems becomes increasingly important, as long-term effects on marine biota are largely unknown, encouraging studies on the hazards posed by their use through biological models (Corsi et al., 2014). Phytoplankton is a key component of the microbiota community. It forms the basis of the aquatic trophic networks, and any change in the natural population of phytoplankton can affect the structure of aquatic biota. The effects of 13 commercial sunscreens were studied on the growth rate of the marine phytoplankton Chaetoceros gracilis commonly found in Western Mediterranean Sea (Tovar-Sanchez et al., 2013). A relatively high average half maximal effective concentration (EC50) after $72 \mathrm{~h}$ incubation was obtained at $125 \pm 71 \mathrm{mg} \mathrm{L}^{-1}$, with no distinction of the sunscreen components or UV-filters involved in these products. While different studies highlighted the ecotoxicity of some organic UV-filters on marine systems like coral reef (bleaching) and particularly on marine organisms such as crustaceans, echinoderms and algae (Danovaro et al., 2008; Fent et al., 2010; Downs et al., 2016), the status of mineral and nanoparticulate UV-filters remains under consideration. Despite $\mathrm{TiO}_{2}$ nanoparticles are among the most studied ENMs to evaluate the overall risk related to nanomaterials, the majority of these studies on marine systems deal with the anatase or P25 $\mathrm{TiO}_{2}$ forms (Minetto et al., 2014), which are not relevant analogs of sunscreen UV-filters. Indeed, $\mathrm{TiO}_{2}$ based UV-filters consist not only of the rutile form, they are also always functionalised in surface, all these characteristics certainly modifying the nanomaterial reactivity and toxicity (Labille and Brant, 2010; Gerloff et al., 2012). Large knowledge gaps thus remain regarding the marine eco-toxicity of relevant mineral UV-filters.

The hydrogen peroxide produced by three commercial sunscreens in marine system under solar radiation was studied with different UV-filter compositions and as a function of time (Sanchez-Quiles and Tovar-Sanchez, 2014; Sendra et al., 2017). It revealed that the sunscreens containing $\mathrm{TiO}_{2}$ or $\mathrm{ZnO}$-based UVfilters produced 797.7 and $424.8 \mathrm{nmol} \mathrm{ROS} / \mathrm{mg}$ of nanoparticles respectively, while a sunscreen free of these two mineral UVfilters, but containing only organic UV-filters, generated 59- and 31-times lower ROS respectively. No information was provided on the nature of the ENM coatings found in these products. Such high ROS production was measured during maximum solar radiation and caused toxicity in the phytoplankton population. Differential sensitivity of microalgae to sunscreens and $\mathrm{TiO}_{2}$ ENMs can produce a change in the dynamics of phytoplankton populations and provoke undesirable ecological effects, such as giving dinoflagellates more prominence (Sendra et al., 2017). Even if the authors note that many other components in the sunscreens, including additional organic UV-filters, may also contribute to ROS production, these results raise the question of the nanoparticulate UV-filters inertness once released in the environment, i.e., what is the lifetime of the photo-passivating layer originally present at the nanoparticle surface?

Among marine organisms, the sea urchin is globally distributed in almost all depths, latitudes, temperatures, and environments in the ocean and plays a dominant role in structuring and functioning of the rocky reef ecosystem (Pinsino and Matranga, 2015). It possesses an extraordinary adaptive capability for adjusting to environmental changes, which enables us to learn about the molecular signaling pathways involved in protection, robustness and plasticity (Smith et al., 2008). Moreover, a good understanding of gene functions and developmental Gene Regulatory Networks (GRN) and a close genetic relationship to humans all together make sea urchin an attractive and emerging probing model to monitor the state of marine environmental health and to study the ENM safety/toxicity both at the cellular and molecular levels. Paracentrotus lividus has been nominated for inclusion on the list of alternative animal models presented by the EPAA (European Partnership for Alternative Approaches to Animal Testing) committed to pooling knowledge and resources to accelerate the development, validation and acceptance of alternative approaches to promote the replacement, reduction, and refinement (3Rs) of animal use in regulatory testing. Pioneering eco-toxicological and immuno-toxicological experimental 
studies were carried out with free-living $P$. lividus by Matranga et al. (2006); Pinsino et al. (2008), Pinsino and Matranga (2015), and Migliaccio et al. (2019). Nevertheless, most of the research on the ecotoxicity of ENMs on sea urchins thus far has been focused on the embryonic development and carried out according to classical toxicological criteria: dose- and time-dependent responses, analysis of the effects on development and analysis of the tissues accumulating nano/micromaterial such as metaloxide, metal, carbon-based particles (Fairbairn et al., 2011; Buric et al., 2015; Mesaric et al., 2015; Alijagic and Pinsino, 2017). However, precise and predictive linkages between laboratory and natural exposures (unrealistic and realistic) have not yet been established, and future work on sunscreen residues should tackle these points, considering for example direct and indirect release into the sea and the possible transformations underwent before internalisation by living organisms.

The existence of a protein corona was detected at the ENM surface upon their entering in the biological medium (MarquesSantos et al., 2018), indicating that the ENMs interact with the components constituting the biological medium, which alters both their bioavailability and toxicity. Similar interaction was also observed with commercial $\mathrm{TiO}_{2}$ UV-filters exposed to the P. lividus immune cells in vitro (Alijagic et al., 2019; Catalano, 2020). Cellular responses seem to depend on the composition of the corona in vivo and in vitro. For example, the main constituents of the protein corona on the surface of $\mathrm{TiO}_{2} \mathrm{NP}$ exposed to the supernatant of cultured sea urchin immune cells were identified as a subset of adhesion and cytoskeletal proteins (Alijagic et al., 2019). Primary sea urchin immune cell cultures show how simplified cell model can inform our understanding of complex networks in intact organism on focusing on the role of extracellular protein/peptide molecules/metabolites/other signals involved in cellular communication and potential particle functionalization (Pinsino and Alijagic, 2019). The potential immune-toxicity of a few metal oxide nanoparticles, including $\mathrm{TiO}_{2}$ was investigated in vivo, pointing out the potential pathway that can be involved in the interaction with immune cell (Falugi et al., 2012; Pinsino et al., 2015). For example, the biological regulatory mechanism in signal transduction underlying the effects of $\mathrm{TiO}_{2}$ nanoparticles on P. lividus immune cell behavior in vivo, demonstrated that phagocytes interact with these particles eliciting a receptor-mediated phagocytic mechanism involving Toll-like receptor 4 (TLR4)/p38 MAPK signaling pathway without eliciting an inflammatory response or other harmful effects on biological functions (Pinsino et al., 2015). In analogy, $\mathrm{TiO}_{2}$ nanoparticle activates suppressive mechanisms by down-regulating the expression of genes encoding immunerelated and apoptotic proteins, elicits metabolic rewiring by boosting the immune cell antioxidant activity and restores homeostasis by keeping at physiological levels some key immunerelated proteins, in vitro (Alijagic et al., 2020).

\section{Biological Effects on Freshwater Systems}

Sunscreen usage may affect the quality of freshwater systems via multiple routes. Not only recreational areas near rivers and lakes constitute a major input during the summer season but, in addition, most of the effluents produced by domestic wastewater treatment, that may contain sunscreen residues, are released to surface water. In their review on $\mathrm{ZnO}$ and $\mathrm{TiO}_{2}$ inorganic UV filters, Schneider and Lim (2019) included the environmental effects on fish, coral, and algae. Among the works cited therein, biological effects of $\mathrm{ZnO}$ nanoparticles were measured and discussed with regard to the $\mathrm{Zn}^{2+}$ ionic form. However, it is worthwhile noting that these studies referred to bare $\mathrm{ZnO}$ nanoparticles, which do not take into account the passivating role of the surface layer generally found on mineral UV filters. As mentioned earlier, this layer is likely to favor biocompatibility and to screen any chemical reactivity related to the $\mathrm{TiO}_{2}$ or $\mathrm{ZnO}$ core. This point can explain some contradictory data in the literature. For instance, Corinaldesi et al. (2018) measured a lower impact (coral bleaching) of two commercial nano- $\mathrm{TiO}_{2}$ UV filters than bare $\mathrm{ZnO}$ nanoparticles on tropical stony corals, certainly because the former was made more biocompatible thanks to the surface coating. Conversely, Hanigan et al. (2018) measured abnormal embryogenesis in zebrafish more pronounced with $\mathrm{TiO}_{2}$ than with $\mathrm{ZnO}$ UV filters, both extracted from a commercial sunscreen. In this latter work, one can hypothesize that the ENM surface coatings were altered during the sunscreen treatment in the organic solvent used to extract the ENMs from the matrix, as revealed by the high photo-induced reactivity of the $\mathrm{TiO}_{2}$ ENM measured by the authors.

The effect of the surface coating on $\mathrm{ZnO}$ nanoparticles was studied by Yung et al. on the ecotoxic response of exposed algaes (Yung et al., 2017). The authors prepared ZnO ENMs coated with a hydrophilic or a hydrophobic layer, using silane coatings similar to what could be used in UV filter synthesis. They also studied non-coated $\mathrm{ZnO}$ ENMs for comparison. After $96 \mathrm{~h}$ of exposure at varying $\mathrm{ZnO}$ concentrations from 0.1 to $100 \mathrm{mg} / \mathrm{L}$, they found that the hydrophilic and the non-coated $\mathrm{ZnO}$ were more potent at inhibiting growth of algal cells than the hydrophobic $\mathrm{ZnO}$. It remains in question to what extent this difference resulted from a reduced exposure of the algal cells to $\mathrm{ZnO}$ with the hydrophobic coating, since the hydrophobic ENM surface could favor aggregation, adsorption or flotation. The authors also pointed out that the uncoated $\mathrm{ZnO}$ ENM generally formed larger aggregates, but was more soluble than the two coated ZnO ENMs. This was certainly due to some steric repulsion induced by the organic coating between the coated nanoparticles, favoring their dispersion, while the additional surface layer hindered the dissolution of the $\mathrm{ZnO}$ core.

In order to assess the ecotoxicity and transfer of nanoparticulate UV filters through the food chain, an ENM consisting of a nano- $\mathrm{TiO}_{2}$ core coated with $\mathrm{Al}(\mathrm{OH})_{3}$ and PDMS was aged under simple aquatic conditions and exposed at three levels: algae, microcrustacean and fish (Fouqueray et al., 2012, 2013). The aging process resulted in the loss of the hydrophobic PDMS coating, and the subsequent aqueous dispersion of the ENM-residues (Labille et al., 2010) (see aging reaction in Figure 5). Pseudokirchneriella subcapitata cultures were contaminated with the ENM-residues and a significant association of algae and $\mathrm{TiO}_{2}$ was evidenced 
(Figure 6A). A Daphnia magna dietary chronic exposure of these contaminated algae was performed. It revealed that the $\mathrm{TiO}_{2}$ brought by food was localized in the digestive tract of the daphnia (Figure 6B), in an extent that was correlated to the original algae contamination (Figure 6D). This induced low mortality but decreased growth and reproduction which can be partly related to the modification of the digestive physiology of daphnia. The toxicity of the aged ENMs was also studied on Danio rerio fish as a further step of the food chain (Figure 6C), via this indirect trophic route or by direct food contamination. Indirect and low exposure via the trophic route did not alter fish growth (weight). No modification of energy reserves, digestive and antioxidant enzymes was measured after the 7 days of exposure to contaminated Daphnia as food. However, direct exposure to contaminated food caused a low toxicity on juvenile zebrafish Danio rerio. At the early life stage, premature hatching was observed, possibly due to embryo hypoxia. Moreover, digestive physiology was altered after 14 days of exposure and seemed to be an indirect target of the ENM-residues when provided by food.

\section{RISK RELATED TO INDIRECT RELEASE AT THE PRODUCT END OF LIFE}

Two scenarios were investigated at the end of life of the sunscreen, through liquid and solid wastes: cosmetic products having been rinsed- or washed off, flow to WWTP while packaging waste is subject to various waste management techniques which depend on available infrastructures and consumer habits (Figure 1).

\section{Fate of Sunscreens and Associated ENMs in Solid Waste}

After usage, sunscreen packaging is disposed of primarily as municipal solid waste (MSW) and ends up in landfills or incinerators, or may be recycled. While some investments are made in modern collection, separation and processing systems, and in the packaging type and material(s) to minimize the environmental footprint (Cosmetics Europe TPCA, 2018), the fate through these waste management processes of the unused lotion/cream remaining in the trashed container, and of the involved ENMs, is another potential concern.

The recycling process of plastic packaging often involves cleaning, which generates large volumes of effluent. According to the requirements for emission of wastewater into the domestic sewage, these effluents must be treated before their discharge, so that various waste constituents are removed. The pollutant load in the effluent and its effect on the environment depend on the treatment used. To date, no data dealing with the contribution of cream/lotion residues remaining in sunscreen packaging exists. However, relationships between the effluent quality and the optimization of the washing step have been pointed out (Santos et al., 2005), suggesting that some ENMs contained in the discarded products may ultimately reach domestic sewage via this pathway. Therein, their fate is driven by the wastewater treatment

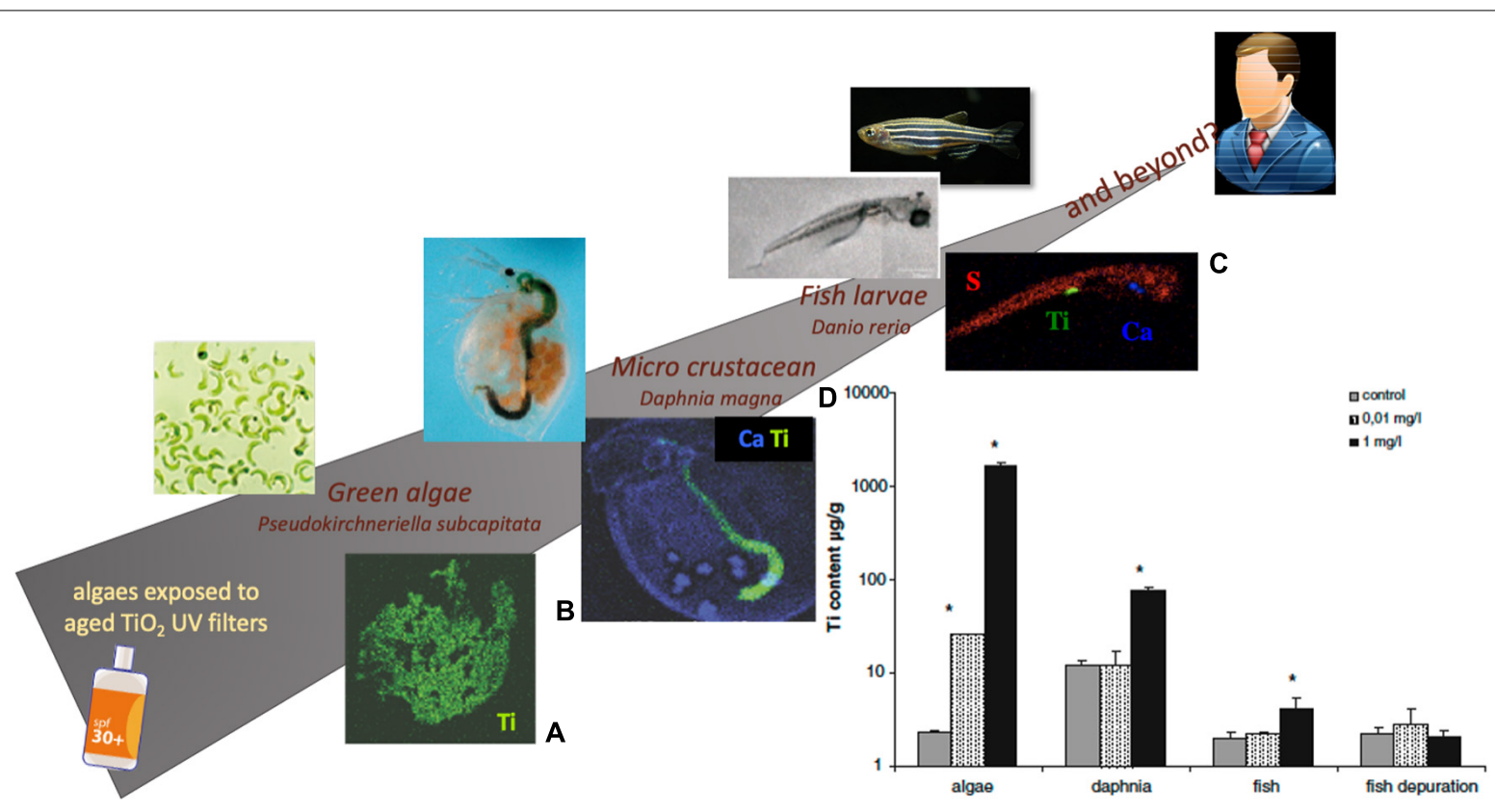

FIGURE 6 | Example of trophic transfer of an aged nano- $\mathrm{TiO}_{2}$ UV-filter, from green algae to micro-crustacean and fish. Elemental mapping of the internalized Ti element after exposure was achieved on P. subcapitata (A), the D. magna (B), and the D. rerio larvae (C), using X-ray microfluorescence. Ca and S maps were also superimposed in Daphnia and $D$. rerio in order to visualize the entire body. Ti quantification in these organisms as a function of the exposure concentration, was realized by ICP-MS analysis coupled to total digestion (D) (Fouqueray et al., 2012, 2013). 
process as detailed in section "Fate of UV-filters in wastewater and sludge."

In a solid waste landfill, the unused lotion remaining in the trashed container may leach toward downstream reservoirs. The extent of this phenomenon depends on many factors, including the integrity of the liners and leachate collection systems, if present (Hennebert et al., 2013). Solid waste leachates typically result from rainwater that percolates through the solid wastes by gravity and mobilizes compounds, either particulate or soluble, that are able to detach/dissolve from the solid matrix. They are generally collected in settling ponds, where leachate sludge is formed by sedimentation. Further management of both the leachate and the formed sludge requires knowledge of the occurrence of pollutants in these reservoirs.

No field data is available regarding ENMs released from sunscreens in this context. The only field study which investigated nano- $\mathrm{TiO}_{2}$ release was dedicated to a construction and demolition waste landfill (Kaegi et al., 2017). It showed that the total elemental $\mathrm{Ti}$ content of the leachate amounted to a few tens of $\mu \mathrm{g} / \mathrm{L}$ and was strongly correlated with total suspended solids. The annual emission of $\mathrm{TiO}_{2}$ particles was estimated to be $0.5 \mathrm{~kg} / \mathrm{y}$, and nanoscale $\mathrm{TiO}_{2}$ particles to $0.5 \mathrm{~g} / \mathrm{y}$, with a predominance of spherically shaped $\mathrm{TiO}_{2}$ particles, indicating their man-made origin from micro- and nanoscale white pigments.

The factors influencing the ENM stability in suspension in landfill leachates have complicated actions and interactions (Bolyard et al., 2013; Part et al., 2018). For example, colloidal organic matter acts mainly as a stabilizer of suspended ENMs, and salinity as an aggregating and precipitating agent. Bolyard et al. (2013) studied the fate of two hydrophobic $\mathrm{TiO}_{2}$ and $\mathrm{ZnO}$ commercial UV-filters that were spiked into leachates obtained from conventional MSW landfills (Bolyard et al., 2013). The ENM coatings were triethoxycaprylylsilane on $\mathrm{ZnO}$ and dimethicone/methicone copolymer and aluminum hydroxide on $\mathrm{TiO}_{2}$. They showed that both ENMs did not affect the biochemical oxidation of organic matter and did not inhibit either aerobic or anaerobic processes. Their findings support the dispersibility of hydrophobic UV-filters in leachates and revealed that the majority of them underwent aggregation, due to interaction with leachate components (such as humic acid) in which they were recovered. This suggests that nanoparticulate UV-filters would likely be recovered in the leachate sludge after sedimentation. A colloidal Ti content of $32 \mu \mathrm{g} / \mathrm{L}$ was detected in 2012 in a landfill leachate (Hennebert et al., 2013). In landfill leachate sludge, the total $\mathrm{Ti}$ concentration ranges from $<5$ to $35 \mathrm{mg} / \mathrm{kg}$ with a mean concentration of $23 \mathrm{mg} / \mathrm{kg}(n=10)$ (Hennebert et al., 2017). This is up to 200 times less than representative concentration in soil, $4000 \mathrm{mg} / \mathrm{kg}$ (Lindsay, 1979) or $2400 \mathrm{mg} / \mathrm{kg}$ (Sposito, 2008), which suggests that the landfill probably acts as an ENM sink.

Regarding sunscreens, the retention of unused cream/lotion in a landfill compared to its transport by the percolating water is determined by the polarity of the formulation. Thus, one can expect that the type of emulsion, $\mathrm{O} / \mathrm{W}$ or $\mathrm{W} / \mathrm{O}$, plays a determining role here, the former being preferably transported in the aqueous leachate. To our knowledge, this key point was not studied in the literature and no published experimental data is available. For this reason, an experimental approach is briefly proposed here (Figure 7), to investigate the effect of the formulation type on the ability of two different nano- $\mathrm{TiO}_{2}$ UV-filters to be removed from the sunscreen container by a landfill leachate. $\mathrm{O} / \mathrm{W}$ and $\mathrm{W} / \mathrm{O}$ sunscreens are formulated in the laboratory with $5 \%$ nano- $\mathrm{TiO}_{2}$, respectively hydrophilic (i.e., $\mathrm{TiO}_{2} / \mathrm{SiO}_{2}$ ) or hydrophobic $\left(\mathrm{TiO}_{2} / \mathrm{Al}_{2} \mathrm{O}_{3} /\right.$ stearic acid). These UV filters were characterized elsewhere (Catalano et al., 2020; Slomberg et al., 2020). A real solid waste leachate is recovered from the settling pond of a municipal landfill. A 1L sample is added to a translucent high-density polyethylene (HDPE) container and $2 \mathrm{~g}$ of sunscreen is applied to the inside of the container lid. The container lid is gently placed on the bottle and the ensemble is agitated end-over-end for 1 day (Figure 7B). After this time, the lid is removed and the leachate is allowed to settle. Samples are taken from the liquid over time. Following this approach, contrasted scenarios could be revealed, depending on the type of sunscreen formulation used. The O/W emulsion with hydrophilic $\mathrm{TiO}_{2}$ (i.e., $\mathrm{TiO}_{2} / \mathrm{SiO}_{2}$ ) would likely show complete leaching from the container lid and transport within the leachate, while most of the W/O emulsion and the hydrophobic $\mathrm{TiO}_{2}\left(\mathrm{TiO}_{2} / \mathrm{Al}_{2} \mathrm{O}_{3} /\right.$ stearic acid) it contains, would remain in the container (Figures 7C,D). Hydrophilic nano- $\mathrm{TiO}_{2}$ entering the leachate would likely be recovered in the leachate sludge after sedimentation since aggregation and settling are likely to occur in the leachate. The lipophilic formulation would be less mobile at the product end-of-life and thus hydrophobic $\mathrm{TiO}_{2} \mathrm{UV}$-filters and W/O sunscreens should be preferred from a "landfilling" point of view.

Incineration is a common process that enables both reduction of the volume of waste and its conversion into energy at the same time. A recent review concluded that incineration of MSW and sewage sludge can concentrate metals from ENMs in the incineration slags or fly ashes. Depending on the incineration method or material (e.g., MSW, sewage sludge, etc.), the mineralogical phase of the solid residues, their associated metal content and the morphology of the inclusions can all be highly variable (Part et al., 2018). For example, the emission behavior of nano- $\mathrm{BaSO}_{4}$ in a MSW incineration plant was studied (roller grate furnace, boiler, dry exhaust gas purification unit, fabric filter, and selective catalytic reduction). It revealed that almost $87 \%$ of the recovered ENMs were found in the bottom ash, $8.5 \%$ in boiler ash, and $4.5 \%$ in residue from fabric filter. The separation efficiency of the fabric filter for the barium sulfate particles was more than 99\%. The authors also pointed out that the tested ENMs tended to sinter at temperatures lower than bulk $\mathrm{BaSO}_{4}$ and exhibited a strong tendency to adhere to fly ash particles after combustion. Indeed, laboratory studies have shown that fusing and sintering usually makes the ENMs non separable from the solid matrix of the ashes (Le Bihan et al., 2017). The residues from waste incineration potentially containing concentrated ENMs will either be landfilled or used for recycling materials (e.g., construction materials). Although there is no data available regarding sunscreens specifically, we can assume that the same process of concentration will occur with the nanoparticulate 


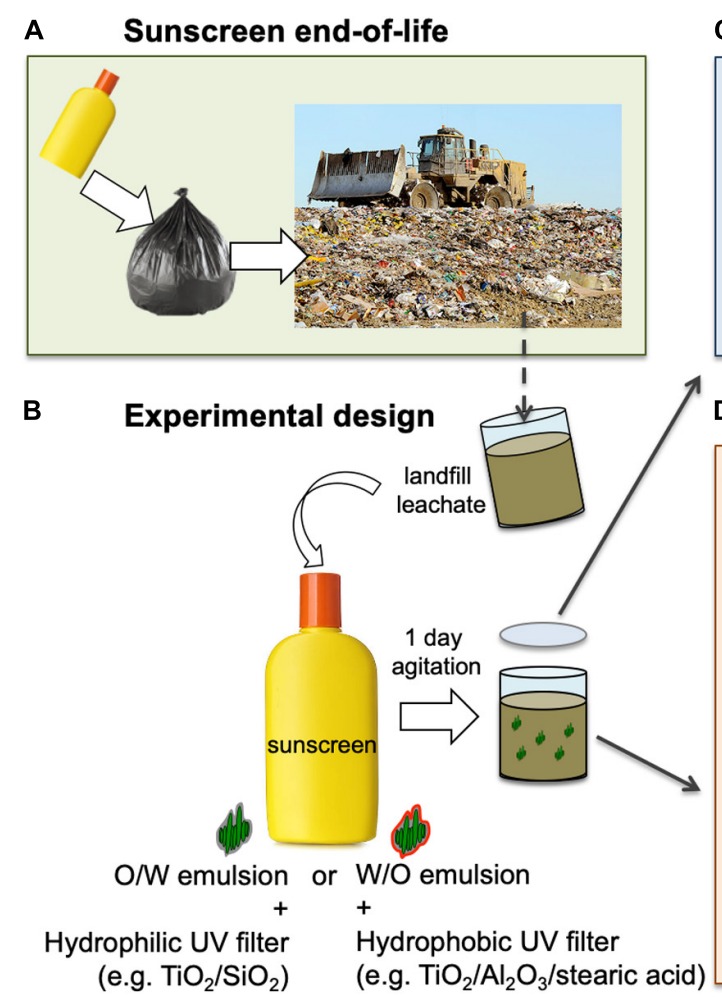

\section{ENM remaining in packaging}

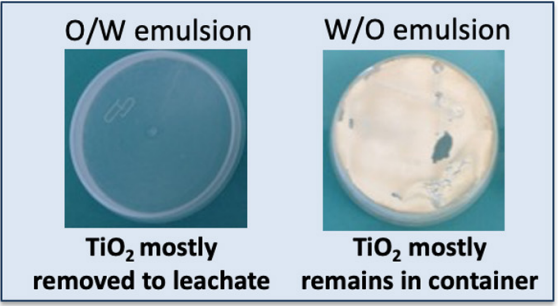

D ENM suspension in leachate

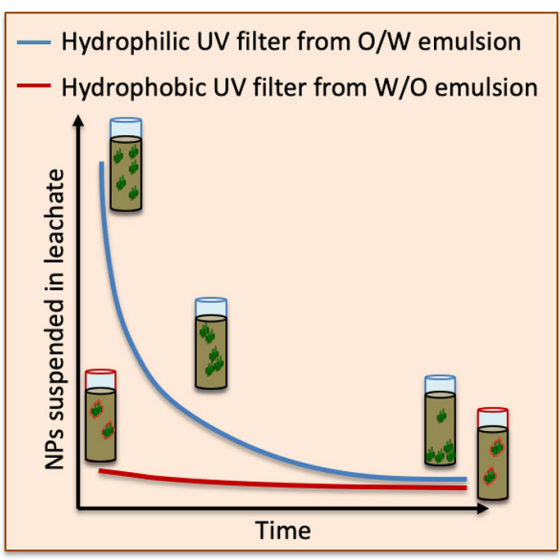

FIGURE 7 | Experimental approach proposed to mimic leaching in solid waste disposal at end of life (A). A sunscreen product in packaging is agitated in a real landfill leachate over 1 day (B). Then, the sunscreen remaining in the packaging is quantified (C) and the ENM suspended in the leachate are quantified over time (D)

UV-filters left in the packaging. During incineration, wastes are oxidized at high operating temperatures of $850-1100^{\circ} \mathrm{C}$ (Part et al., 2018). While the organic components of sunscreens and UV-filters are totally calcined to the $\mathrm{CO}_{2}$ form, the minerals constituting the UV-filters core $\left(\mathrm{TiO}_{2}, \mathrm{ZnO}\right)$ or their coatings (e.g., $\mathrm{SiO}_{2}, \mathrm{Al}_{2} \mathrm{O}_{3}$ ) may have different fates. Titanium dioxide occurs as two important polymorphs, the stable rutile and metastable anatase. Anatase transforms irreversibly to rutile at elevated temperatures, between 550 and about $1000^{\circ} \mathrm{C}$ (Hanaor and Sorrell, 2010), which suggests that the rutile form that is mainly used in UV-filters will not be altered by incineration (Mueller et al., 2013). Nevertheless, the other constituents of the matrix can play a role in determining the final form of the ENM after incineration. Massari et al. (2014) investigated in lab the behavior of $\mathrm{TiO}_{2}$ ENMs during incineration at $950^{\circ} \mathrm{C}$ of solid paint waste containing these particles. They did not observe any release of $\mathrm{TiO}_{2}$ ENM into the atmosphere, but the $\mathrm{Ti}$ underwent physicochemical transformation during the incineration that resulted in a calcium titanate product immobilized in a glass matrix and recovered in the ashes (Massari et al., 2014). Considering the fate of nano- $\mathrm{ZnO}$ during incineration, when under reducing conditions, elemental $\mathrm{Zn}$ starts to evaporate at a temperature of $905^{\circ} \mathrm{C}$. It is assumed to recondensate in the flue gas stream as soon as it cools, but unlikely to return into its nanoscale form (Mueller et al., 2013). Under oxidizing conditions $\mathrm{ZnO}$ remains in a solid state at temperatures up to $1500^{\circ} \mathrm{C}$. Thus, similarly to the fate of $\mathrm{TiO}_{2}$, it is likely that this ENM will accumulate in the bottom ash as a fused-in component and will ultimately end up landfilled (Mueller et al., 2013; Part et al., 2018). Aluminum (hydr)oxides are used as a coating of $\mathrm{TiO}_{2}$ or $\mathrm{ZnO} \mathrm{UV}$-filter. Aluminum hydroxides are the precursors of metastable aluminas. Several polymorphs exist that have a thermal stability increasing with decreasing degree of hydration (Digne et al., 2002). This means that alumina is the stable form recovered after incineration. Finally, under heat treatment, the amorphous silica used as a nanoparticle coating is expected to undergo densification to the glass form due to condensation of $\mathrm{Si}-\mathrm{OH}$ groups into $\mathrm{Si}-\mathrm{O}-\mathrm{Si}$ network bridging units (Kamitsos et al., 1993). It should be noted that these expected respective fates based on the existing scientific literature are only considered individually and do not take into account any matrix effect or pre-existing associations with other phases. Nevertheless, no significant alteration of these mineral constituents of UV-filter is expected from the heat treatment underwent during incineration, so the nanoparticulate forms are expected to remain in the resulting ashes.

Significant knowledge gaps still remain on the fate of ENMs from solid waste disposal that limit our current ability to develop appropriate end-of-life management strategies. There is a need for continued research in this area. No work has been conducted to quantify ENMs present in discarded materials, and an understanding of ENM release from consumer products 
under conditions representative of those found in relevant waste management process is needed (Part et al., 2018).

\section{Fate of UV-Filters in Wastewater and Sludge}

The everyday use of sunscreens results in draining the product with wash water toward sewage treatment plants. The fate of the nanomaterials determines the exposure of different downstream environmental compartments. Two complementary scenarios can be considered: nanomaterials ending up in the sewage sludge may be spread as fertilizing material in agriculture, while those remaining suspended in the treated water would be directly released to surface waters (Figure 1). The respective impacts on soil and river ecosystems thus depend on the WWTP efficiency for ENM removal. A partition coefficient of ENMs from water to the WWTP sludge or landfill can be used by quantifying the substance in the respective compartments in order to estimate the respective fates (Sun et al., 2014; Gottschalk et al., 2015).

An assessment of the fate, behavior and environmental risk associated with sunscreens containing $\mathrm{TiO}_{2}$ ENMs was studied in a UK field scenario (Johnson et al., 2011). It revealed a decrease of concentration from 30 to $3.2 \mu \mathrm{g} / \mathrm{L}$ of $\mathrm{TiO}_{2}$ particles below $0.45 \mu \mathrm{m}$ in size from the influent to the effluent of a treatment plant, suggesting that the majority of the ENMs ends up in the activated sludge. Some topical sunscreen constituents were detected in untreated wastewater, treated wastewater, and biosolids (Balmer et al., 2005). The organic compounds detected in these studies were UV-filter compounds such as 4-MBC (4-methylbenzylidene camphor) and OC (octocrylene), which generally biodegrade slowly and can bioaccumulate. Although nano- $\mathrm{TiO}_{2}$ is unlikely to behave exactly the same way as the other sunscreen components, its low solubility suggests a probable persistence of this substance in the receptacle compartments. However, no studies to date have documented the occurrence of nano- $\mathrm{TiO}_{2}$ specifically from sunscreens in wastewater or natural water bodies receiving wastewater (U.S. EPA, 2010).

The total titanium concentration in WWTP sludge results from the sum of multiple possible sources. It was analyzed in 13 sludge samples from different regions of France. and was found to be present in half of the sludges studied ( 7 out of 13 raw sludges and 4 out of 9 digested sludges), revealing an order of magnitude of $50-400 \mathrm{mg} / \mathrm{kg}$ with a mean concentration of $170 \mathrm{mg} / \mathrm{kg}$ (Hennebert et al., 2017). The Ti speciation was investigated using electron microscope coupled to EDX. Distinct phases bearing $\mathrm{Ti}$, such as areas corresponding to $\mathrm{TiO}_{2} \mathrm{NP}$ aggregates, could not be evidenced. In the raw sludge, Ti was mostly associated with major elements such as $\mathrm{Al}, \mathrm{Ca}, \mathrm{Fe}, \mathrm{K}$, $\mathrm{Mg}, \mathrm{Na}, \mathrm{P}, \mathrm{S}, \mathrm{Si}$, and $\mathrm{Cl}$. The Ti concentration ranged between 1 and $2 \%$ excluding $\mathrm{C}$ and $\mathrm{O}$ elements. Ti was thus part of the organo-mineral matrix constituting the sludge, but it was not homogenously distributed at this scale of observation as it was not identified in all the areas analyzed for a given sludge. Its origin could be anthropogenic, in relation with white paints, toothpastes, food additives, sunscreens and façade run-offs, or pedogenic. Both origins could not be discriminated, as well as the nano or non-nano forms (Hennebert et al., 2017). Distinguishing the different origins of $\mathrm{TiO}_{2}$ in such complex matrix indeed remains an analytical challenge. However, by comparing nano$\mathrm{TiO}_{2}$ characteristics originating from a natural soil and from an anthropic sludge, it was shown that the anthropogenic $\mathrm{TiO}_{2}$ form homo and heteroaggregates of simpler structure, richer in organic matter (Pradas del Real et al., 2018). Thus, studying the morphology of $\mathrm{TiO}_{2}$ particles and their status in the mineralorganic assemblages may provide some insights into their natural or anthropic origin.

The accumulation of ENMs in activated sludge may also eventually affect the bacterial activity in the sludge, and in turn the epuratory effect carried by the local fauna in the water treatment plant. Only considering the effects of ENMs on cell viability and growth of microorganisms does not completely assess their potential environmental risks via the activated sludge. To comprehensively evaluate the potential effects of ENMs on the microorganism functionality, the effects on processes such as nitrogen removal ability and anaerobic digestion should be investigated. The effect of metal oxide nanoparticles, including nano- $\mathrm{TiO}_{2}$, nano- $\mathrm{Al}_{2} \mathrm{O}_{3}$, nano- $\mathrm{SiO}_{2}$ and nano- $\mathrm{ZnO}$, on anaerobic digestion was investigated by fermentation experiments using waste activated sludge as the substrates (Mu et al., 2011). At doses up to 150 milligram per gram total suspended solids (mg/g-TSS), no inhibitory effect was observed, except with $\mathrm{ZnO}$ showing a dose - effect relation. The released $\mathrm{Zn}^{2+}$ from nano- $\mathrm{ZnO}$ was an important reason for its inhibitory effect on methane generation. Higher dosages of nano- $\mathrm{ZnO}$ even inhibited the steps of sludge hydrolysis, acidification and methanation. Biological nitrogen removal was also shown to be affected by $\mathrm{TiO}_{2}$ NPs (Zheng et al., 2011). A denitrifier bacteria, isolated from the activated sludge was used to evaluate the influences of $\mathrm{TiO}_{2} \mathrm{NPs}$ on its nitrogen removal ability (Li et al., 2016). $\mathrm{TiO}_{2}$ had antibacterial effects from 5 to $50 \mathrm{mg} / \mathrm{L}$ due to ROS production, and the microbial diversity of activated sludge was substantially reduced after 7 days of exposure at the highest $\mathrm{TiO}_{2} \mathrm{NP}$ concentration tested, of $50 \mathrm{mg} / \mathrm{L}$. Such effects should be also considered in further lifecycle stages, notably in the context of sludge spreading on soils as fertilizer (see also section "Effects on terrestrial ecosystem").

\section{Mobility of UV-Filters in Soil Porous Media}

Nanoparticulate UV-filters in topical sunscreens could end up in the sludge produced from wastewater treatment plants via domestic sewage. The disposal of this sludge on land likely represents the primary pathway by which ENMs from sunscreens could enter the soil. The Ti occurrence in sludge was calculated at $305 \mathrm{mg} / \mathrm{kg}$ dry weight. Thus, using sludge as a fertilizer at the recommended maximal agricultural application rate would result in a predicted deposition of up to $250 \mathrm{mg} / \mathrm{m}^{2}$ of Ti to soil surfaces (Johnson et al., 2011). The modeled predicted environmental concentration of nano$\mathrm{TiO}_{2}$ from cosmetics in sludge-treated soils is $0.1-3.1 \mathrm{mg}$ $\mathrm{kg}^{-1}$, while that for $\mathrm{ZnO}$ is close to zero $\left(<0.03 \mu \mathrm{g} / \mathrm{kg}^{-1}\right)$ 
(Sun et al., 2014; Gottschalk et al., 2015). Besides, direct discharge into recreational waters accounts for a significant increase in $\mathrm{TiO}_{2}$ ENMs suspended in water, which may end up in porous systems like sediments, soils or aquifers. The $\mathrm{TiO}_{2}$ ENMs suspended in percolating water can undergo sedimentation (Gondikas et al., 2018) and/or filtration through these porous media, depending on the physico-chemical parameters of the medium.

Conventionally, the study of pollutant transfer through porous media, nanoparticulate or not, is based on experiments using a percolation column filled with the porous medium and connected to a quantitative monitoring of the pollutant in the outlet, using in-line analytical techniques (Spectrometry $\mathrm{UV} /$ fluorescence, conductivity) or offline after collection (atomic absorption spectrometry, ICP-MS). Mainly pure or mineralcoated quartz sand (Joo et al., 2009; Solovitch et al., 2010), and limestone (Esfandyari Bayat et al., 2015) are used as porous media, and most of the studies that address the transfer of $\mathrm{TiO}_{2}$ or ZnO ENMs in porous media deal with bare NPs. Only a few of them consider the role of particle coating, although it obviously alters the particle surface properties, by screening or increasing the surface charge or changing the surface area for instance, and the interactions with the soil minerals accordingly. This point was clearly demonstrated by comparing the transfer of bare $\mathrm{TiO}_{2}$ or $\mathrm{ZnO}$ ENMs and their coated counterparts, either with carboxymethyl cellulose (CMC) (Joo et al., 2009; Kanel and Al-Abed, 2011) or partially crosslinked polyacrylic acid (PAA) (Petosa et al., 2012), in a sand-packed column. The conclusions drawn from these studies were concordant: while rapid aggregation was observed with the uncoated ENMs, even at low ionic strength, the coated $\mathrm{TiO}_{2}$ ENMs were significantly more stable in a large range of ionic strengths (up to 100$200 \mathrm{mM} \mathrm{NaNO}$ ) (Petosa et al., 2012), which was assigned to the shift of the point of zero charge (PZC) toward lower $\mathrm{pH}$ values (which increased the negative charge at the $\mathrm{pH}$ of the experiments) as well as to the steric barrier in the case of the adsorbed CMC layer. Even if similar interfacial reactions exist in the case of CMC-coated $\mathrm{ZnO}$ ENMs, the Zn mobility in the column followed a more complex trend that was correlated to the ENM solubility, which was also dependent of $\mathrm{pH}$ (Kanel and Al-Abed, 2011). The zeta potential measurement of the particles and of the porous system in the various media tested can be considered as determining in the affinity and thus the retention of nanoparticles with respect to the porous medium collector, and should allow a better understanding. Subsequently, uncoated $\mathrm{TiO}_{2}$ NPs showed high retention on the sand whereas their coated counterparts were much more mobile in the same conditions, thus highlighting the importance of considering not only the nature of the core of the ENMs but also the composition of their shell (if relevant) in contamination assessment.

$\mathrm{TiO}_{2}$ ENMs used in sunscreens fall into this category of surface-modified particles that will certainly behave differently from bare $\mathrm{TiO}_{2}$ NPs of the same crystallinity (rutile) and primary size (50-100 nm), particularly in terms of surface charge and surface hydro/lipophilicity (see section "Biological effects on marine organisms"). The question was raised by
Englehart et al. (2016) who specifically investigated the influence of a polymer additive (TEGO carbomer) used in commercial sunscreens on the transport of a $\mathrm{TiO}_{2}$ (78\% anatase, $14 \%$ rutile, and $8 \%$ amorphous) suspension through a quartz sand column. TEGO is an acrylate/C10-C30 alkyl acrylate crosspolymer designed for emulsion thickening, close to the PAA investigated elsewhere (Petosa et al., 2012). The results show the same trends, with a net tendency to aggregation and retention in the porous medium for uncoated $\mathrm{TiO}_{2}$, enhanced with increasing ionic strength (from deionized water to $3 \mathrm{mM} \mathrm{NaCl}$ ) whereas the addition of TEGO carbomer decreased the PZC, stabilized the suspension, and resulted in greater recovery of the particles eluted from the column. Again, enhancement of $\mathrm{TiO}_{2}$ mobility was demonstrated, with the risk of larger pollution dispersion in the environment with a hydrophilic stabilizing agent compared to uncoated $\mathrm{TiO}_{2}$ ENMs which are usually considered in most studies.

Parameters of the porous medium such as the nature (Joo et al., 2009), grain size and heterogeneity (Lv et al., 2016) were also shown to play a significant role in the behavior of $\mathrm{TiO}_{2}$ ENM transfer rate. Environmentally relevant $\mathrm{Fe}$ and $\mathrm{Al}$ hydroxide coated quartz sand resulted in delayed breakthrough curves compared with pure quartz sand for CMC-coated $\mathrm{TiO}_{2}$ ENMs (Joo et al., 2009). These observations were assigned to an increased surface of the metal hydroxide coated collector, to the possible formation of chelates between CMC and the adsorbed metal hydroxides, and to the reduction of the net negative charge of the collector. Retention of $\mathrm{TiO}_{2}$ ENMs was also increased with decreasing the sand grain size while heterogeneity introduced in the column by packing it with two types of sand (coarse and fine) revealed the occurrence of preferential (faster) flow pathways that induced faster and greater transport than expected in the homogeneous sand bed. The environmental significance of such finding is important, particularly in fracture-containing rocks, as confirmed by the study reported by Ollivier et al. (2018): contrary to the usual packed sand bed, the column was composed of a drill core of a fractured Schist rock containing quartz, feldspar, phyllosilicates and iron oxides with a low porosity (6\% compared with $30-50 \%$ in the case of packed sand beds). With this configuration, and despite interaction energy profiles favorable to particle retention, which was observed to occur specifically on the minerals along the fractures, $\mathrm{TiO}_{2}$ ENMs were partially transferred through the rock.

Other investigations related to the flow-through solutions (chemistry, $\mathrm{pH}$, ionic strength, and velocity) were made for the fate of bare $\mathrm{TiO}_{2}$ NPs. They basically show that poorer stability leading to greater deposition occurs with divalent cations $\left[\mathrm{Ca}^{2+}\right.$ (Joo et al., 2009; Petosa et al., 2012) or $\mathrm{Mg}^{2+}$ (Esfandyari Bayat et al., 2015)] compared with monovalent $\mathrm{Na}^{+}$at identical ionic strength. The same conclusions can be drawn with a decrease in $\mathrm{pH}$ and/or an increase in ionic strength (Joo et al., 2009; Solovitch et al., 2010; Labille et al., 2012; Petosa et al., 2012; Esfandyari Bayat et al., 2015). Naturally occurring colloids have also a significant role in increasing the transport of $\mathrm{TiO}_{2}$ through a porous medium when unfavorable attachment is obeyed (Cai et al., 2016). 
Finally, Chowdhury et al. (2011) raised the mechanisms of straining and blocking to explain their unexpected results where they obtained the greatest retention of $\mathrm{TiO}_{2}$ NPs under electrostatically unfavorable deposition and significant elution from the column under favorable conditions. They also hypothesized the possible break-up of the attached aggregates via hydrodynamic forces when high flow velocity is applied, supported by the fact that the size of the eluted particles was smaller than that in the influent (aggregated) suspension. Hence, partial release of the previously deposited particles is susceptible to happen under flow increase (Godinez and Darnault, 2011), or by reducing the electrolyte concentration (or ionic strength) as demonstrated by Godinez et al. (2013).

Field experiments of transfer can also be proposed via tracer test experiments. These experiments in real environmental conditions are usually more difficult to carry out and to interpret due to additional features of the solid/liquid system, such as complexity of the medium, fracturation or inhomogeneity of the rock that induce preferential pathways. However, these largescale experiments are needed to confirm (or not) the labscale column experiments (Cary et al., 2015).

\section{Effects on Terrestrial Ecosystem}

The practice of activated sludge or "biosolid" spreading is a source of contamination of agricultural soils from which ENMs may enter the food webs or cause direct and indirect toxicity to plants, microbial communities, or other soil organisms. This was evidenced on bacterial communities of grassland soils exposed to different doses of $\mathrm{TiO}_{2}$ or $\mathrm{ZnO}$ nanoparticles in microcosms over 60 days (Ge et al., 2011). Both nanoparticles reduced microbial biomass and diversity and altered the composition of the soil bacterial community, with a stronger effect with nano- $\mathrm{ZnO}$ than with nano- $\mathrm{TiO}_{2}$ at the same exposure concentration $(0.5 \mathrm{mg}$ $\mathrm{g}^{-1}$ soil). The stronger impact of $\mathrm{ZnO}$ ENM on soil due to its higher solubility was also evidenced in a study where biosolids produced from a pilot wastewater treatment plant were used to amend a soil with controlled and relevant ENM loads (Chen et al., 2015). The effects of Ag, $\mathrm{ZnO}$, and $\mathrm{TiO}_{2}$ ENMs added to the soil via the biosolids were monitored via toxicogenomic responses over a 6 months of exposure. In response to ENM exposure, many of the identified biological pathways, gene ontologies, and individual genes were associated with nitrogen metabolism, nodulation, metal homeostasis, and stress responses. Results showed inhibition of nodulation with ENM treatment primarily due to phytotoxicity likely caused by enhanced bioavailability of $\mathrm{Zn}$ ions. Very few data are available regarding the effects of $\mathrm{TiO}_{2}$ or $\mathrm{ZnO}$ ENMs on soil via biosolid amendment and none of the experiments thus far had been carried out with a real UV-filter. The potential role of the ENM coating remains mostly unknown in such a system. With this in mind, an experimental approach is proposed here to mimic in the lab a realistic scenario where a sunscreen containing nano- $-\mathrm{TiO}_{2}$ is released from a domestic wash water to the wastewater treatment plant, ending up in the biosolids that are then used for cultivated soil amendment (Figure 8). Briefly, a sunscreen containing a known amount of nano- $\mathrm{TiO}_{2}$ (e.g., 5\%) can be aged in synthetic shower water (mineral water, $20 \mathrm{mg} / \mathrm{L}$ solid soap, $40^{\circ} \mathrm{C}, 5$ min.) at $314 \mathrm{mg} / \mathrm{L}$ (Figure 8A). This nano- $\mathrm{TiO}_{2}$ concentration is calculated using the average amount of sunscreen product consumed when applied to an entire adult body ( $15.7 \mathrm{~g}$, Ficheux et al., 2016) and the average volume of water consumed per shower. Chronic injections of this freshly prepared wash water should then be added into an aerobic bioreactor over 1 month to achieve a final nano- $\mathrm{TiO}_{2}$ concentration of $\sim 70-360 \mathrm{mg}$ nano$\mathrm{TiO}_{2} / \mathrm{kg}$ in the dried biosolids (Figure 8B). This concentration corresponds to that estimated in biosolids (Lazareva and Keller, 2014; Gottschalk et al., 2015). Finally, plants can be cultured in a real soil amended with these biosolids (1-10 $\mathrm{mg}$ nano- $-\mathrm{TiO}_{2} / \mathrm{kg}$ amended soil) (Figure 8C) (Sun et al., 2014). A fast-growing, agriculturally relevant plant is recommended (e.g., rapeseed Brassica napus), so that the experiment takes a reasonable time (e.g., 30 days). A control experiment is required in parallel using the same sunscreen formulated without the nano- $\mathrm{TiO}_{2} \mathrm{UV}$-filter. Biological effects due to the presence of the nano- $-\mathrm{TiO}_{2} \mathrm{UV}$-filter can be investigated through direct phytotoxic effects on plant growth, as well as indirect effects on soil microbial communities and plant defense systems.

In an exhaustive literature review on the toxicity of manufactured $\mathrm{ZnO}$ nanoparticles to ecological receptors such as bacteria, plants, and terrestrial, invertebrates and vertebrates (Ma et al., 2013), Ma et al. (2013) commented that more than $50 \%$ of the studies reviewed suggest $\mathrm{ZnO} \mathrm{NP}$ dissolution to ionic zinc contributes at least partially, if not completely, to the toxicity observed. A second key property raised by the authors is the photoreactivity of the $\mathrm{ZnO}$ ENM, which can cause photoinduced toxicity. In spite of an abundant literature existing on the ecotoxic effects of $\mathrm{ZnO} \mathrm{ENM}$, there is little available data regarding real nano-ZnO UV filters, and the effects of the ENM coating or formulation on these two key properties determining the ecotoxicity are mostly unknown. The effect of a nano-ZnO UV filter extracted from a sunscreen was studied on E. coli (Baek et al., 2017). The authors investigated the antibacterial and toxicity pathways and compared the sunscreen extract to an industrial $\mathrm{ZnO}$ ENM reference. At very high exposure dosage $(80-1280 \mathrm{mg} / \mathrm{L})$, they could observe a growth inhibition rate proportional to the $\mathrm{ZnO}$ concentration and less pronounced with the sunscreen extract as compared to the industrial ZnO ENM. However, we can not conclude here on a possible protective effect of the ENM coating used in sunscreen, because the authors hypothesized that the ENM size could be a determining parameter in the toxicity pathway, as the sunscreenextracted ENM was larger in size $(225 \mathrm{~nm})$ than the industrial reference $(110 \mathrm{~nm})$.

A research consortium has also been devoted to studying the effects of a nano- $\mathrm{TiO}_{2}$-based UV filter on different soil organism endpoints. The ENM case study consisted of a $\mathrm{TiO}_{2}$ nanoparticulate core originally coated with $\mathrm{Al}(\mathrm{OH})_{3}$ and polydimethylsiloxane (PDMS) layers and that was first aged under aqueous conditions. The resulting aged nano- $\mathrm{TiO}_{2}$ had lost most of its PDMS coating and in the end displayed a hydrophilic $\mathrm{Al}(\mathrm{OH})_{3}$ surface chemistry favoring aqueous dispersion and bio accessibility (Figure 5). To determine the mutagenic potential of the aged nano- $\mathrm{TiO}_{2}$ on bacteria, the bacterial reverse mutation test (Ames test) was modified and 


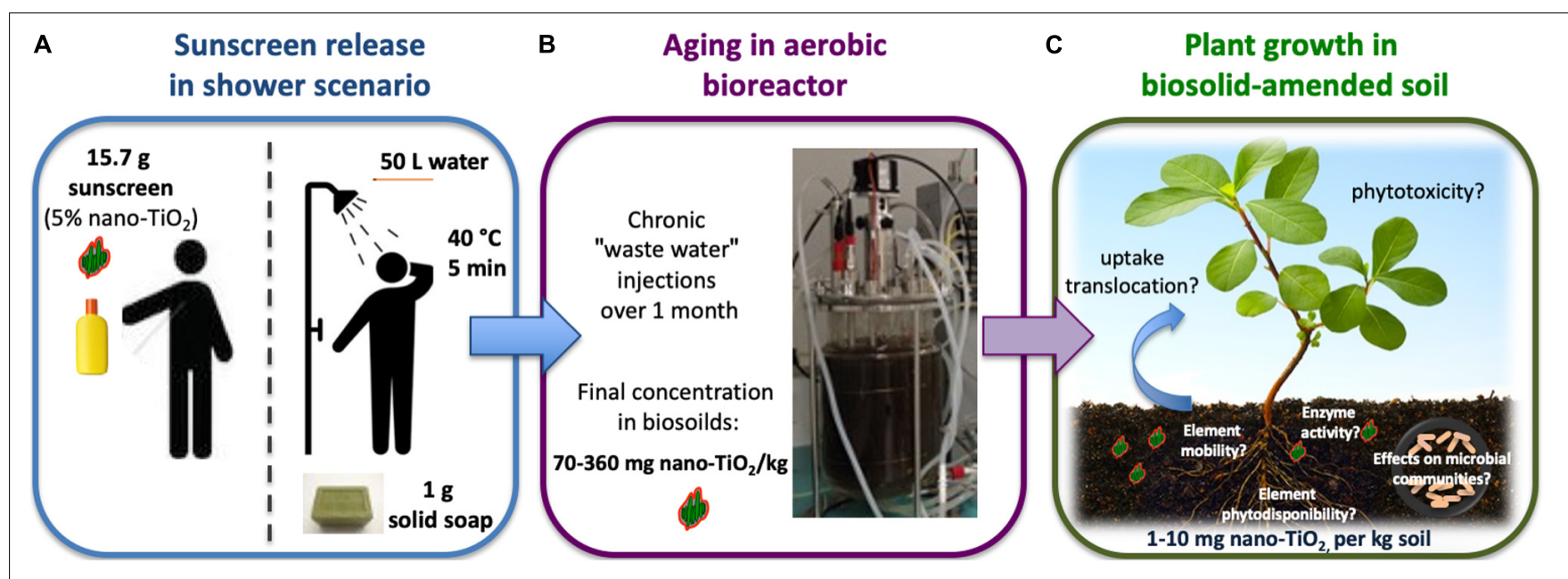

FIGURE 8 | Experimental approach to mimic (A) sunscreen and nano-TiO 2 release in a shower scenario, (B) subsequent aging in aerobic waste water treatment, and (C) end-of-life in biosolid-amended soil.

used with Salmonella typhimurium strains (Jomini et al., 2012). A relatively high exposure concentration from 1 to $100 \mathrm{mg} / \mathrm{L}$ was used. Mutagenicity was evidenced and more pronounced on a mutant strain, which suggested an oxidative stress-mediated mechanism. At lower exposure concentrations, Escherichia coli was used to study the effects on cell physiology (Santaella et al., 2014). The aged nano- $\mathrm{TiO}_{2}$ first appeared safe, as it had no effect on the viability of $E$. coli nor on the mutant impaired in oxidative stress, did not induce mutagenesis and did not impair the integrity of membrane lipids. Nevertheless, when pre-exposed to the aged nano- $\mathrm{TiO}_{2}$ under low intensity UV light, cells turned out to be more sensitive to cadmium, a priority pollutant widely disseminated in soils and surface waters. This behavior was not due to a Trojan Horse effect but was certainly related to the ROS production by the aged nano- $\mathrm{TiO}_{2}$ under UV exposure. These results highlighted how the possible effects of UV-filters should be studied not only individually, but also in combination with other environmental pollutants, in order to deal with a possible cocktail effect.

In order to evaluate the behavior, uptake and ecotoxicity of the aged nano- $\mathrm{TiO}_{2}$ on earthworms, Eisenia fetida worms were exposed to ENM suspensions at $0.1,1$, and $10 \mathrm{mg} / \mathrm{L}$ for $24 \mathrm{~h}$ (Bigorgne et al., 2011). This constituted a favored route of exposure to worms with regard to the more relevant soil pathway. Only worms exposed at the highest concentration showed detectable bioaccumulation of titanium, increasing expression of metallothionein and superoxide dismutase mRNA and induction of apoptotic activity. No cytotoxicity could be observed on coelomocytes, but a significant decrease of phagocytosis was observed starting from $0.1 \mathrm{mg} / \mathrm{L}$. These results suggested that under such condition, bioaccumulation and ROS production could be responsible for the alteration of the antioxidant system in worms. The soil and food routes of exposure were also studied on the earthworm Lumbricus terrestris at concentrations ranging from 0 to $100 \mathrm{mg} \mathrm{kg}^{-1}$ (Lapied et al., 2011). Note that the modeled predicted concentration of nano- $\mathrm{TiO}_{2}$ in sludge-treated soil ranges at lower level 0.1 to $3.1 \mathrm{mg} \mathrm{kg}^{-1}$ soil (Gottschalk et al., 2015). No mortality was observed, but an increased apoptotic frequency in cuticule, intestinal epithelium and chloragogenous tissue was measured. The aged nano- $\mathrm{TiO}_{2}$ did not cross the intestinal epithelium/chloragogenous matrix barrier to enter the coelomic liquid, or the cuticule barrier to reach the muscular layers, so no bioaccumulation could be evidenced under these conditions of exposure.

Finally, the aged nano- $-\mathrm{TiO}_{2}$ was also tested on the plant model Vicia faba, exposed via a liquid medium during $48 \mathrm{~h}$ (Foltete et al., 2011). While, no change compared to controls could be observed on plant growth, photosystem II maximum quantum yield, genotoxicity or phytochelatins levels, the measurement of $\mathrm{Ti}$ and $\mathrm{Al}$ concentrations in roots revealed ENM internalization in superficial root tissues. This suggested that eventual long-term effects on plants may occur. Up-to-date analytical tools have been developed that enable to measure chemical mapping and speciation in complex samples in order to give insights on the internalization, localization/interactions of ENM in/with plants (Castillo-Michel et al., 2017).

\section{REGULATIONS REGARDING NANOPARTICLES IN COSMETICS AND OTHER SUBSTANCES}

Depending on countries, sun care products are regulated as cosmetics or as Over-The-Counter (OTC) drugs (Risk and Policy Analysts Limited, 2004). OTC means they are strictly regulated and require pre-market registration. Regardless of how they are regulated, all of these sunscreen regulations have analogies. Each country has a pre-approved list of permitted UV-filters, an accepted method of running efficacy by SPF determination, and regulated labels (Steinberg, 2007). United States, Europe, Australia, Canada, and South Korea have approved the use of $\mathrm{TiO}_{2}$ as a UV-filter in sunscreens 
with a maximum concentration of $25 \%$ (U.S. EPA, 2010). In the USA, the Food and Drug Administration regulation on sunscreens (FDA, 2000, 2014) does not distinguish between conventional and nanoscale $\mathrm{TiO}_{2}$, between anatase and rutile, or between coated and uncoated particles. However it is important to note that some states have enforced additional requirements, such as California warning on $\mathrm{TiO}_{2}$ of respirable size (OEHHA, 2020), or Hawaii and Florida banning oxybenzone and octinoxate (Hawaii State Legislature, 2018). Recently, in February 2019, the FDA rule was updated to address concerns regarding safety and efficacy of active ingredients, testing methods, dosage and labeling requirements (FDA, 2019). This rule describes the conditions under which the OTC sunscreen monograph products are generally recognized as safe and effective and not misbranded. An important point is the new status given to organic UV filters. Considering that current knowledge does not contain sufficient data to support the use of the UV filters cinoxate, dioxybenzone, ensulizole, homosalate, meradimate, octinoxate, octisalate, octocrylene, padimate $\mathrm{O}$, sulisobenzone, oxybenzone, and avobenzone as safe and effective, they were listed as Category III. Additional information on these ingredients are requested so that FDA can evaluate their status. Indeed, both an increased sunscreen consumption and exposure and an evolving information about the potential risks associated with these products have led FDA to recommend such additional needs. The rapid internalization of some organic filters by the human body after sunscreen usage, that was recently evidenced (Matta et al., 2019, 2020), certainly constitutes a major basis for this recommendation. As for mineral UV filters, the FDA considers that sufficient safety data on both zinc oxide and titanium dioxide were produced to support the proposal that sunscreen products containing these ingredients (at concentrations up to 25\%) would be safe and effective (Category I). There is no doubt that such new recommendation will soon increase the proportion of mineral-based products on the US sunscreen market.

In Europe, while the Cosmetics Regulation. 1223/2009 (Eur-Lex, 2009) allows 24 organic molecules and two mineral particles as UV filters, it also requires that manufacturers indicate the presence of nanomaterials in the list of cosmetics ingredients on the product packaging. Annexe VI of the present cosmetics regulation lists the four nanomaterials substances that are expressly authorized as UV-filters in cosmetics in 2018: nano-zinc oxide ( $\mathrm{ZnO}$ ), nano-titanium dioxide $\left(\mathrm{TiO}_{2}\right)$, nano-TBPT (tris-biphenyl triazine), and nanoMBBT (methylene bis-benzotriazolyl tetramethylbutylphenol). It should be noted that $\mathrm{ZnO}$ was approved late by the European Cosmetic Regulation, which only included it since 2016 in Annex VI, as some interrogations were remaining regarding the safety of its nano-form (SCCS, 2012). Moreover, since January 2020, the regulatory requirements under EU $\mathrm{REACH}$ regulation for substances in nanoform produced or imported over $1 \mathrm{t} / \mathrm{y}$, have to be completed as a dossier that addresses new specific questions such hazard fate and exposure, in the aim of minimizing the associated risk (Eur-Lex, 2018).

\section{CONCLUSION}

In this review, we discussed the environmental risk associated with nanomaterials used as UV-filters in sunscreen. All stages of the product lifecycle, from its manufacture to its end of life, through the consumer use were considered in order to discuss the state of the art on both the exposure and hazard of these substances in the respective environmental receptacles. This included sunscreen design regarding both the safest UV-filter selection and the formulation optimization, the aquatic environment and living organisms directly exposed via bathing activity, or indirectly exposed via domestic wastewater pathways; and the product disposal at its end of life. From these considerations, some recommendations can be proposed for a safe-by-design approach that could be helpful not only to manufacturers and regulators, but also to consumers in their decision criteria to select a product.

Nanoparticulate UV-filters based on $\mathrm{TiO}_{2}$ core were the particular focus of this review as they constitute a main active ingredient of mineral sunscreens. However, $\mathrm{ZnO}$ was also considered here as an alternative mineral UV-filter when scientific literature exists. Despite an abundance of scientific literature on the risk associated with bare $\mathrm{TiO}_{2}$ nanomaterials, a main output of this review is that such bare $\mathrm{TiO}_{2}$ nanomaterials are not representative candidates for the risk evaluation of $\mathrm{TiO}_{2}$ based UV-filters. Indeed, the external coating applied industrially on the UV-filters gives them specific surface properties that largely determine both fate, exposure and hazard of the nanomaterial, often independently of the $\mathrm{TiO}_{2}$ core. The same recommendation stands with $\mathrm{ZnO}$ UV-filters that generally come with a man-made coating. The nature and lifetime within aging of the nanomaterial coating are thus key variables to account for in evaluating the associated risk. At present, knowledge gaps remain regarding the safety of nanomaterials used in sunscreen, as very few previous studies have been devoted to real sunscreen formulations. Moreover, systematic studies comparing different nanomaterials in one given formulation to highlight the effects of the nanoparticulate UV-filters in sunscreen safety are still lacking.

Guidelines in developing a safe-by-design sunscreen may differ according to the lifecycle stage considered, so that in a global consideration, each respective point should be integrated in order to minimize the overall risk by anticipation. Moreover, they should also be put in perspective with the respective knowledge about organic UV-filters safety in the same stages, since both mineral and organic UV-filter types are often balanced for selection criteria.

\section{Consumer's Health}

Even if the effect of the UV-filter on a consumer's health via topical application was not explored in this review, any recommendation for a safer product should certainly consider the propensity to penetrate through the skin barrier, as this feature may largely determine the eventual exposure to the substance. Here, nanoparticulate and organic UV-filters have very contrasted characteristics. While a safe skin is supposed to remain mostly impermeable to nanoparticles (Poland et al., 2013), it was 
recently demonstrated that many organic UV-filters are able to rapidly reach the consumer's blood after passing the skin barrier (Matta et al., 2019, 2020). The UV-filter solubility is definitely a key characteristic here, as particulate substances of low solubility (e.g., $\mathrm{TiO}_{2}, \mathrm{MBBT}$ nano) should be less likely to pass the skin barrier than dissolved molecules (e.g., avobenzone, octocrylene...). Meanwhile, particulate substances of high solubility such as $\mathrm{ZnO}$ nanoparticles are also prone to dissolve into ionic species that may easily pass the skin barrier (Gulson et al., 2010, 2012, 2015; Mohammed et al., 2019). Nevertheless, these are physiological ions that are not deemed to be dangerous and do not appear to cause any local toxicity at physiological concentration (Mohammed et al., 2019). Overall, any tendency to skin penetration should logically be inversely correlated to the environmental release, meaning that these two aspects should be weighed distinctly in a safe by design effort.

\section{Environmental Release}

The propensity of a sunscreen to be washed off the skin logically determines how much is being released directly into aquatic environment, particularly through recreational activities, vs. how much will end up in domestic wastewater treatment plant via daily cleansing. Although very few data are available regarding the retention factor of sunscreens on skin, the "water resistant" label found on some products obeys rules that indirectly suggest a high retention of the UV-filters on the skin (Cosmetics Europe TPCA, 2005). The ingredients of the sun care product can control the water resistance by creating a hydrophobic structure that is unfavorable to being washed off. Water in oil emulsions would be considered as the best choice in this aim (Leroy and Deschamps, 1986).

\section{Environmental Impacts on Aquatic Systems}

Whether the UV-filters released in aquatic environments end up suspended in the water column, sedimented, or floating at the surface determines the type of environmental media and living organisms most impacted by these substances. Colloidal transport implies a lower concentration due to dilution and a possible exposure to planktonic organisms. Sedimentation following aggregation favors in situ accumulation and implies a higher local concentration and exposure to benthic organisms. Finally, flotation of the most hydrophobic residues at the water surface may favor locally and temporary high UV-filter concentration, depending on weather and photodegradation. For nanoparticulate UV-filters, the preferential fate scenario and hazards are mostly determined by the nature and lifetime of the external coating. For example, aqueous dispersion can be limited with a hydrophobic feature on one hand, while hazards may be minimized with biocompatible and resistant coating features on the other hand. Moreover, the UVfilter photostability is an additional characteristic for which a compromise must be found. While we seek to maximize it on the skin for longer term sun protection, it also determines the substance recalcitrance in the environment. Organic molecules rapidly photodegraded and insoluble nanoparticles give antagonist features here.

\section{Environmental Effects Through the Product End of Life}

The fate and effects of UV-filters at the end of life of sunscreen products are probably the least documented points of their lifecycle. They may follow different routes, including, e.g., landfilling and activated sludge spreading on soil, beyond which the possible transfer to downstream environmental systems is mostly unknown. Nevertheless, similar key questions as in aquatic systems shall be considered here, dealing with the formulation aging and nanomaterial surface properties, that control both the dispersion tendency and chemical reactivity.

Sun damage is an ever-present danger that leads to myriads of deleterious effects on the exposed skin, including early skin aging and skin cancer. Since our modern lifestyle is not compatible with staying in the shadow, skin protection including antiUV clothes and sunscreen must remain a priority to protect ourselves against these effects, and even to save lives. In many countries, regulations exist to control the composition, labeling and efficacy of sunscreens in blocking UV rays, so that consumers with no special knowledge can buy and use such products with confidence. Now, with the rising concern about environmental impacts of anthropic activities, sunscreen effects on the environment are also questioned. While their usage is not under debate and must remain a health priority, sunscreen composition can still be optimized with regard to the environment. By making, in advance, the appropriate choices that help minimize or prevent the environmental impact of the sunscreen UV-filters along with the product lifecycle, a sustainable design can be achieved. Whether it be industrial cosmetic formulators or policy makers in charge of safety and regulation, the provided risk knowledge can help lead to improvements in the assessment and management of cosmetics containing nanoparticulate UVfilters. Furthermore, the results of the present work will help provide better information for consumers and allow for easier decision-making for manufacturers and regulators.

\section{AUTHOR CONTRIBUTIONS}

JL: conceptualization, funding acquisition, project administration, resources, supervision, validation, and original draft writing. RC: data curation, formal analysis, and figure conceptualization. DS: conceptualization, original draft writing, data curation, and formal analysis. SM and AP: conceptualization, supervision, original draft writing, data curation, formal analysis, and validation. $\mathrm{PH}$ : original draft writing. CS: conceptualization. VB: data curation and formal analysis. All authors contributed to the article and approved the submitted version.

\section{FUNDING}

This work is a contribution to the Labex Serenade (no. ANR11-LABX-0064) funded by the "Investissements d'Avenir" French Government program of the French National Research Agency (ANR) through the A*MIDEX project (no. ANR-11-IDEX-0001-02). 


\section{REFERENCES}

Alijagic, A., Benada, O., Kofronova, O., Cigna, D., and Pinsino, A. (2019). Sea urchin extracellular proteins design a complex protein corona on titanium dioxide nanoparticle surface influencing immune cell behavior. Front. Immunol. 10:2261. doi: 10.3389/fimmu.2019.02261

Alijagic, A., Gaglio, D., Napodano, E., Russo, R., Costa, C., Benada, O., et al. (2020). Titanium dioxide nanoparticles temporarily influence the sea urchin immunological state suppressing inflammatory-relate gene transcription and boosting antioxidant metabolic activity. J. Hazard Mater. 384:121389. doi: 10.1016/j.jhazmat.2019.121389

Alijagic, A., and Pinsino, A. (2017). Probing safety of nanoparticles by outlining sea urchin sensing and signaling cascades. Ecotoxicol. Environ. Saf. 144, 416-421. doi: 10.1016/j.ecoenv.2017.06.060

Auffan, M., Pedeutour, M., Rose, J., Masion, A., Ziarelli, F., Borschneck, D., et al. (2010). Surface structural degradation of TiO2-based nanomaterial used in cosmetics. Environ. Sci. Technol. 44, 2689-2694. doi: 10.1021/es903757q

Baek, S., Joo, S. H., Kumar, N., and Toborek, M. (2017). Antibacterial effect and toxicity pathways of industrial and sunscreen $\mathrm{ZnO}$ nanoparticles on Escherichia coli. J. Environ. Chem. Eng. 5, 3024-3032. doi: 10.1016/j.jece.2017. 06.009

Balmer, M. E., Buser, H. R., Muller, M. D., and Poiger, T. (2005). Occurrence of some organic UV filters in wastewater, in surface waters, and in fish from Swiss lakes. Environ. Sci. Technol. 39, 953-962. doi: 10.1021/es040055r

Bigorgne, E., Foucaud, L., Lapied, E., Labile, J., Botta, C., Sirguey, C., et al. (2011). Ecotoxicological assessment of $\mathrm{TiO} 2$ byproducts on the earthworm Eisenia fetida. Environ. Pollut. 159, 2698-2705. doi: 10.1016/j.envpol.2011.05.024

Bluthgen, N., Zucchi, S., and Fent, K. (2012). Effects of the UV filter benzophenone3 (oxybenzone) at low concentrations in zebrafish (Danio rerio). Toxicol. Appl. Pharmacol. 263, 184-194. doi: 10.1016/j.taap.2012.06.008

Bolyard, S. C., Reinhart, D. R., and Santra, S. (2013). Behavior of engineered nanoparticles in landfill leachate. Environ. Sci. Technol. 47, 8114-8122.

Botta, C., Labille, J., Auffan, M., Borschneck, D., Miche, H., Cabie, M., et al. (2011). $\mathrm{TiO} 2$-based nanoparticles released in water from commercialized sunscreens in a life-cycle perspective: structures and quantities. Environ. Pollut. 159, 1543-1548.

Boxall, A., Chaudhry, Q., Sinclair, C., Jones, A., Aitken, R., Jefferson, B., et al. (2007). Current and Future Predicted Environmental Exposure to Engineered Nanoparticles. York: Central Science Laboratory.

Braun, J. H., Baidins, A., and Marganski, R. E. (1992). Tio2 pigment technology - a review. Prog. Organ. Coat. 20, 105-138.

Buric, P., Jaksic, Z., Stajner, L., Sikiric, M. D., Jurasin, D., Cascio, C., et al. (2015). Effect of silver nanoparticles on Mediterranean sea urchin embryonal development is species specific and depends on moment of first exposure. Mar. Environ. Res. 111, 50-59. doi: 10.1016/j.marenvres.2015.06.015

Cai, L., Peng, S., Wu, D., and Tong, M. (2016). Effect of different-sized colloids on the transport and deposition of titanium dioxide nanoparticles in quartz sand. Environ. Pollut. 208, 637-644. doi: 10.1016/j.envpol.2015.10.040

Calafat, A. M., Wong, L. Y., Ye, X. Y., Reidy, J. A., and Needham, L. L. (2008). Concentrations of the sunscreen agent benzophenone- 3 in residents of the United States: national health and nutrition examination survey 2003-2004. Environ. Health Perspect. 116, 893-897. doi: 10.1289/ehp.11269

Cary, L., Pauwels, H., Ollivier, P., Picot, G., Leroy, P., Mougin, B., et al. (2015). Evidence for $\mathrm{TiO} 2$ nanoparticle transfer in a hard-rock aquifer. J. Contaminant. Hydrol. 179, 148-159. doi: 10.1016/j.jconhyd.2015.06.007

Castillo-Michel, H. A., Larue, C., Pradas del Real, A. E., Cotte, M., and Sarret, G. (2017). Practical review on the use of synchrotron based micro- and nano$\mathrm{X}$-ray fluorescence mapping and $\mathrm{X}$-ray absorption spectroscopy to investigate the interactions between plants and engineered nanomaterials. Plant Physiol. Biochem. 110, 13-32. doi: 10.1016/j.plaphy.2016.07.018

Catalano, R. (2020). Evaluation and Anticipation of the Risks Associated to Nanoparticulate UV Filters used in Sunscreens - A Lifecycle-Oriented Study, in Department of Environmental Sciences. Ph.D. thesis of Aix-Marseille University, Aix-en-Provence.

Catalano, R., Masion, A., Ziarelli, F., Slomberg, D., Laisney, J., Unrine, J., et al. (2020). Optimizing the dispersion of nanoparticulate TiO2-based UV filters in a non-polar medium used in sunscreen formulations - the roles of surfactants and particle coatings. Colloid. Surf. A 599, 124792. doi: 10.1016/j.colsurfa.2020. 124792

Chen, C., Unrine, J. M., Judy, J. D., Lewis, R. W., Guo, J., McNear, D. H. Jr., et al. (2015). Toxicogenomic responses of the model legume medicago truncatula to aged biosolids containing a mixture of nanomaterials $(\mathrm{TiO}(2), \mathrm{Ag}$, and $\mathrm{ZnO})$ from a pilot wastewater treatment plant. Environ. Sci. Technol. 49, 8759-8768. doi: 10.1021/acs.est.5b01211

Chowdhury, I., Hong, Y., Honda, R. J., and Walker, S. L. (2011). Mechanisms of $\mathrm{TiO} 2$ nanoparticle transport in porous media: role of solution chemistry, nanoparticle concentration, and flowrate. J. Colloid Interface Sci. 360, 548-555. doi: 10.1016/j.jcis.2011.04.111

Contado, C., and Pagnoni, A. (2010). TiO2 nano- and micro-particles in commercial foundation creams: field flow-fractionation techniques together with ICP-AES and SQW Voltammetry for their characterization. Anal. Methods 2, 1112-1124.

Corinaldesi, C., Marcellini, F., Nepote, E., Damiani, E., and Danovaro, R. (2018). Impact of inorganic UV filters contained in sunscreen products on tropical stony corals (Acropora spp.). Sci. Total Environ. 637-638, 1279-1285. doi: 10.1016/j.scitotenv.2018.05.108

Corsi, G. N. I, Cherr, H. S., Lenihan, J., Labille, M., Hassellov, L., Canesi, F., et al. (2014). Common strategies and technologies for the ecosafety assessment and design of nanomaterials entering the marine environment. ACS Nano 8, 9694-9709. doi: 10.1021/nn504684k

Cosmetics Europe TPCA (2005). Guidelines for Evaluating Sun Product Water Resistance. Brussels: Cosmetics Europe TPCA, 13.

Cosmetics Europe TPCA (2018). Environmental Sustainability: The European Cosmetics Industry's Contribution. Brussels: Cosmetics Europe TPCA, 20.

Dan, Y., Shi, H., Stephan, C., and Liang, X. (2015). Rapid analysis of titanium dioxide nanoparticles in sunscreens using single particle inductively coupled plasma-mass spectrometry. Microchem. J. 122, 119-126. doi: 10.1016/j.microc. 2015.04.018

Danovaro, R., Bongiorni, L., Corinaldesi, C., Giovannelli, D., Damiani, E., Astolfi, P., et al. (2008). Sunscreens cause coral bleaching by promoting viral infections. Environ. Health Perspect. 116, 441-447. doi: 10.1289/ehp.10966

Digne, M., Sautet, P., Raybaud, P., Toulhoat, H., and Artacho, E. (2002). Structure and stability of aluminum hydroxides: a theoretical study. J. Phys. Chem. B 106, 5155-5162. doi: 10.1021/jp014182a

Domingos, R. F., Tufenkji, N., and Wilkinson, K. J. (2009). Aggregation of titanium dioxide nanoparticles: role of a fulvic acid. Environ. Sci. Technol. 43, 1282-1286. doi: 10.1021/es8023594

Downs, C. A., Kramarsky-Winter, E., Segal, R., Fauth, J., Knutson, S., Bronstein, O., et al. (2016). Toxicopathological effects of the sunscreen UV filter, oxybenzone (Benzophenone-3), on coral planulae and cultured primary cells and its environmental contamination in hawaii and the US Virgin Islands. Arch. Environ. Contaminat. Toxicol. 70, 265-288. doi: 10.1007/s00244-015-0227-7

Duong-Ly, K., and Gabelli, S. (2014). Salting out of proteins usingammonium sulfate precipitation. Methods Enzymol. 541, 85-94. doi: 10.1016/b978-0-12420119-4.00007-0

Dzumedzey, Y., Labille, J., Cathala, B., Moreau, C., and Santaella, C. (2017). Polysaccharide coating on environmental collectors affects the affinity and deposition of nanoparticles. Nanoimpact 5, 83-91. doi: 10.1016/j.impact.2016. 12.004

Englehart, J., Lyon, B. A., Becker, M. D., Wang, Y., Abriola, L. M., and Pennell, K. D. (2016). Influence of a polymer sunscreen additive on the transport and retention of titanium dioxide nanoparticles in water-saturated porous media. Environ. Sci. Nano 3, 157-168. doi: 10.1039/c5en00174a

Englert, B. C. (2007). Nanomaterials and the environment: uses, methods and measurement. J. Environ. Monitor. 9, 1154-1161.

Esfandyari Bayat, A., Junin, R., Derahman, M. N., and Samad, A. A. (2015). TiO2 nanoparticle transport and retention through saturated limestone porous media under various ionic strength conditions. Chemosphere 134, 7-15. doi: 10.1016/ j.chemosphere.2015.03.052

Eur-Lex (2009). Regulation (EC) No 1223/2009 of the European Parliament and of the Council of 30 November 2009 on cosmetic products. OJL 342, 59-209.

Eur-Lex (2018). COMMISSION REGULATION (EU) 2018/1881 of 3 December 2018 amending regulation (EC) No 1907/2006 of the European Parliament and 
of the Council on the registration, evaluation, authorisation and restriction of chemicals (REACH) as regards Annexes I, III,VI, VII, VIII, IX, X, XI, and XII to address nanoforms of substances. OJL 308, 1-20.

Euromonitor International (2015). Beauty and Personal Care. London: Euromonitor International.

Fairbairn, E. A., Keller, A. A., Madler, L., Zhou, D. X., Pokhrel, S., and Cherr, G. N. (2011). Metal oxide nanomaterials in seawater: linking physicochemical characteristics with biological response in sea urchin development. J. Hazard. Mater. 192, 1565-1571. doi: 10.1016/j.jhazmat.2011.06.080

Fairhurst, D., and Mitchnick, M. A. (1997). "Particulate sun blocks: general principles," in Sunscreens: Development, Evaluation, and Regulatory Aspects, eds N. J. Lowe, N. A. Shaath, and M. A. Pathak (New York, NY: Marcel Dekker Inc).

Falugi, C., Aluigi, M. G., Chiantore, M. C., Privitera, D., Ramoino, P., Gatti, M. A., et al. (2012). Toxicity of metal oxide nanoparticles in immune cells of the sea urchin. Mar. Environ. Res. 76, 114-121. doi: 10.1016/j.marenvres.2011. 10.003

Faure, B., Salazar-Alvarez, G., Ahniyaz, A., Villaluenga, I., Berriozabal, G., De Miguel, Y. R., et al. (2013). Dispersion and surface functionalization of oxide nanoparticles for transparent photocatalytic and UV-protecting coatings and sunscreens. Sci. Technol. Adv. Mater. 14:023001. doi: 10.1088/1468-6996/14/2/ 023001

FDA (2000). Sunscreen Drug Products for Over-the-Counter Human Use; Final Monograph; Extension of Effective Date; Reopening of Administrative Record. Silver Spring, MD: Food and Drug Administration.

FDA (2014). Sunscreen Innovation Act (SIA). Silver Spring, MD: Food and Drug Administration.

FDA (2019). Sunscreen Drug Products for Over-the-Counter Human Use, in 201903019. Silver Spring, MD: Food and Drug Administration.

Fel, J. P., Lacherez, C., Bensetra, A., Mezzache, S., Beraud, E., Leonard, M., et al. (2019). Photochemical response of the scleractinian coral Stylophora pistillata to some sunscreen ingredients. Coral Reefs 38, 109-122. doi: 10.1007/s00338018-01759-4

Fent, K., Kunz, P. Y., Zenker, A., and Rapp, M. (2010). A tentative environmental risk assessment of the UV-filters 3-(4-methylbenzylidene-camphor), 2ethyl-hexyl-4-trimethoxycinnamate, benzophenone-3, benzophenone-4 and 3benzylidene camphor. Mar. Environ. Res. 69, S4-S6.

Ficheux, A. S., Chevillotte, G., Wesolek, N., Morisset, T., Dornic, N., Bernard, A., et al. (2016). Consumption of cosmetic products by the French population second part: amount data. Food Chem. Toxicol. 90, 130-141. doi: 10.1016/j.fct. 2016.02.008

Foltete, A.-S., Masfaraud, J.-F., Bigorgne, E., Nahmani, J., Chaurand, P., Botta, C., et al. (2011). Environmental impact of sunscreen nanomaterials: ecotoxicity and genotoxicity of altered $\mathrm{TiO} 2$ nanocomposites on Vicia faba. Environ. Pollut. 159, 2515-2522. doi: 10.1016/j.envpol.2011.06.020

Fouqueray, M., Dufils, B., Vollat, B., Chaurand, P., Botta, C., Abacci, K., et al. (2012). Effects of aged $\mathrm{TiO} 2$ nanomaterial from sunscreen on Daphnia magna exposed by dietary route. Environ. Pollut. 163:55. doi: 10.1016/j.envpol.2011. 11.035

Fouqueray, M., Noury, P., Dherret, L., Chaurand, P., Abbaci, K., Labille, J., et al. (2013). Exposure of juvenile Danio rerio to aged $\mathrm{TiO} 2$ nanomaterial from sunscreen. Environ. Sci. Pollut. Res. 20, 3340-3350. doi: 10.1007/s11356-012$1256-7$

Fujishima, A., Zhang, X. T., and Tryk, D. A. (2008). TiO2 photocatalysis and related surface phenomena. Surf. Sci. Rep. 63, 515-582. doi: 10.1016/j.surfrep.2008. 10.001

Gamer, A. O., Leibold, E., and van Ravenzwaay, B. (2006). The in vitro absorption of microfine zinc oxide and titanium dioxide through porcine skin. Toxicol. In Vitro 20, 301-307. doi: 10.1016/j.tiv.2005.08.008

Ge, Y., Schimel, J. P., and Holden, P. A. (2011). Evidence for negative effects of TiO2 and $\mathrm{ZnO}$ nanoparticles on soil bacterial communities. Environ. Sci. Technol. 45, 1659-1664. doi: 10.1021/es103040t

Gerloff, K., Fenoglio, I., Carella, E., Kolling, J., Albrecht, C., Boots, A. W., et al. (2012). Distinctive toxicity of $\mathrm{TiO} 2$ rutile/anatase mixed phase nanoparticles on Caco-2 cells. Chem. Res. Toxicol. 25, 646-655. doi: 10.1021/tx200334k

Giokas, D. L., Salvador, A., and Chisvert, A. (2007). UV filters: from sunscreens to human body and the environment. Trac Trends Anal. Chem. 26, 360-374. doi: 10.1016/j.trac.2007.02.012
Godinez, I. G., and Darnault, C. J. G. (2011). Aggregation and transport of nano$\mathrm{TiO} 2$ in saturated porous media: Effects of $\mathrm{pH}$, surfactants and flow velocity. Water Res. 45, 839-851. doi: 10.1016/j.watres.2010.09.013

Godinez, I. G., Darnault, C. J. G., Khodadoust, A. P., and Bogdan, D. (2013). Deposition and release kinetics of nano- $\mathrm{TiO} 2$ in saturated porous media: effects of solution ionic strength and surfactants. Environ. Pollut. 174, 106-113. doi: 10.1016/j.envpol.2012.11.002

Gondikas, A., von der Kammer, F., Kaegi, R., Borovinskaya, O., Neubauer, E., Navratilova, J., et al. (2018). Where is the nano? Analytical approaches for the detection and quantification of $\mathrm{TiO} 2$ engineered nanoparticles in surface waters. Environ. Sci. Nano 5, 313-326. doi: 10.1039/c7en00952f

Gondikas, A. P., von der Kammer, F., Reed, R. B., Wagner, S., Ranville, J. F., and Hofmann, T. (2014). Release of $\mathrm{TiO} 2$ nanoparticles from sunscreens into surface waters: a one-year survey at the old danube recreational lake. Environ. Sci. Technol. 48, 5415-5422. doi: 10.1021/es405596y

Gottschalk, F., Lassen, C., Kjoelholt, J., Christensen, F., and Nowack, B. (2015). Modeling flows and concentrations of nine engineered nanomaterials in the Danish environment. Int. J. Environ. Res. Public Health 12, 5581-5602. doi: 10.3390/ijerph120505581

Gottschalk, F., Scholz, R. W., and Nowack, B. (2010). Probabilistic material flow modeling for assessing the environmental exposure to compounds: methodology and an application to engineered nano-TiO2 particles. Environ. Modell. Softw. 25, 320-332. doi: 10.1016/j.envsoft.2009.08.011

Gottschalk, F., Sun, T. Y., and Nowack, B. (2013). Environmental concentrations of engineered nanomaterials: review of modeling and analytical studies. Environ. Pollut. 181, 287-300. doi: 10.1016/j.envpol.2013.06.003

Graubner, V. M., Jordan, R., and Nuyken, O. (2004). Photochemical modification of cross-linked poly(dimethylsiloxane) by irradiation at 172 nm. Macromolecules 37, 5936-5953.

Gulson, B., McCall, M., Korsch, M., Gomez, L., Casey, P., Oytam, Y., et al. (2010). Small amounts of zinc from zinc oxide particles in sunscreens applied outdoors are absorbed through human skin. Toxicol. Sci. 118, 140-149. doi: 10.1093/ toxsci/kfq243

Gulson, B., McCall, M. J., Bowman, D. M., and Pinheiro, T. (2015). A review of critical factors for assessing the dermal absorption of metal oxide nanoparticles from sunscreens applied to humans, and a research strategy to address current deficiencies. Arch. Toxicol. 89, 1909-1930. doi: 10.1007/s00204-015-1564-z

Gulson, B., Wong, H., Korsch, M., Gomez, L., Casey, P., McCall, M., et al. (2012). Comparison of dermal absorption of zinc from different sunscreen formulations and differing UV exposure based on stable isotope tracing. Sci. Total Environ. 420, 313-318. doi: 10.1016/j.scitotenv.2011.12.046

Hanaor, D., and Sorrell, C. (2010). Review of the anatase to rutile phase transformation. J. Mater. Sci. 46, 855-874.

Hanigan, D., Truong, L., Schoepf, J., Nosaka, T., Mulchandani, A., Tanguay, R. L., et al. (2018). Trade-offs in ecosystem impacts from nanomaterial versus organic chemical ultraviolet filters in sunscreens. Water Res. 139, 281-290. doi: 10.1016/ j.watres.2018.03.062

Hawaii State Legislature (2018). Environment; Water Pollution; Sunscreen; Oxybenzone; Octinoxate; Sale; Distribution; Prohibition, in SB2571, S.D.2, H.D.2, C.D.1. Honolulu, HI: Hawaii State Legislature.

Hennebert, P., Anderson, A., and Merdy, P. (2017). Mineral nanoparticles in waste: potential sources, occurrence in some engineered nanomaterials leachates, municipal sewage sludges and municipal landfill sludges. J. Biotechnol. Biomater. 7:261.

Hennebert, P., Avellan, A., Yan, J. F., and Aguerre-Chariol, O. (2013). Experimental evidence of colloids and nanoparticles presence from 25 waste leachates. Waste Manage. 33, 1870-1881. doi: 10.1016/j.wasman.2013.04.014

Herrera Melian, J. A., Dona Rodriguez, J. M., Viera Suarez, A., Tello Rendon, E., Valdes do Campo, C., Arana, J., et al. (2000). The photocatalytic disinfection of urban waste waters. Chemosphere 41, 323-327. doi: 10.1016/s0045-6535(99) 00502-0

Jeon, S.-k, Kim, E.-j, Lee, J., and Lee, S. (2016). Potential risks of TiO2 and $\mathrm{ZnO}$ nanoparticles released from sunscreens into outdoor swimming pools. J. Hazard. Mater. 317, 312-318. doi: 10.1016/j.jhazmat.2016.05.099

Johnson, A. C., Bowes, M. J., Crossley, A., Jarvie, H. P., Jurkschat, K., Jurgens, M. D., et al. (2011). An assessment of the fate, behaviour and environmental risk associated with sunscreen $\mathrm{TiO} 2$ nanoparticles in UK field 
scenarios. Sci. Total Environ. 409, 2503-2510. doi: 10.1016/j.scitotenv.2011. 03.040

Jomini, S., Labille, J., Bauda, P., and Pagnout, C. (2012). Modifications of the bacterial reverse mutation test reveals mutagenicity of $\mathrm{TiO} 2$ nanoparticles and byproducts from a sunscreen TiO2-based nanocomposite. Toxicol. Lett. 215, 54-61. doi: 10.1016/j.toxlet.2012.09.012

Joo, S. H., Al-Abed, S. R., and Luxton, T. (2009). Influence of carboxymethyl cellulose for the transport of titanium dioxide nanoparticles in clean silica and mineral-coated sands. Environ. Sci. Technol. 43, 4954-4959. doi: 10.1021/ es900329d

Kaegi, R., Englert, A., Gondikas, A., Sinnet, B., von der Kammer, F., and Burkhardt, M. (2017). Release of TiO2 - (Nano) particles from construction and demolition landfills. Nanoimpact 8, 73-79. doi: 10.1016/j.impact.2017.07.004

Kamitsos, E. I., Patsis, A. P., and Kordas, G. (1993). Infrared-reflectance spectra of heat-treated sol-gel-derived silica. Phys. Rev. B Condens. Matter. 48, 1249912505. doi: 10.1103/physrevb.48.12499

Kanel, S. K., and Al-Abed, S. R. (2011). Influence of $\mathrm{pH}$ on the transport of nanoscale zinc oxide in saturated porous media. J. Nanopart. Res. 13, 40354047. doi: 10.1007/s11051-011-0345-8

Keller, A. A., Vosti, W., Wang, H. T., and Lazareva, A. (2014). Release of engineered nanomaterials from personal care products throughout their life cycle. J. Nanopart. Res. 16:2489.

King, D. M., Liang, X. H., Burton, B. B., Akhtar, M. K., and Weimer, A. W. (2008). Passivation of pigment-grade $\mathrm{TiO}(2)$ particles by nanothick atomic layer deposited SiO(2) films. Nanotechnology 19:255604. doi: 10.1088/0957-4484/19/ $25 / 255604$

Kunz, P. Y., and Fent, K. (2006). Multiple hormonal activities of UV filters and comparison of in vivo and in vitro estrogenic activity of ethyl-4-aminobenzoate in fish. Aquat. Toxicol. 79, 305-324. doi: 10.1016/j.aquatox.2006.06.016

Kunz, P. Y., and Fent, K. (2009). Estrogenic activity of ternary UV filter mixtures in fish (Pimephales promelas) - an analysis with nonlinear isobolograms. Toxicol. Appl. Pharmacol. 234, 77-88. doi: 10.1016/j.taap.2008.09.032

Labille, J., and Brant, J. (2010). Stability of nanoparticles in water. Nanomedicine 5, 985-998.

Labille, J., Feng, J. H., Botta, C., Borschneck, D., Sammut, M., Cabie, M., et al. (2010). Aging of $\mathrm{TiO}(2)$ nanocomposites used in sunscreen. Dispersion and fate of the degradation products in aqueous environment. Environ. Pollut. 158, 3482-3489. doi: 10.1016/j.envpol.2010.02.012

Labille, J., Harns, C., Bottero, J. Y., and Brant, J. (2015). Heteroaggregation of titanium dioxide nanoparticles with natural clay colloids under environmentally relevant conditions. Environ. Sci. Technol. 48, 10690-10698. doi: $10.1021 /$ es $501655 \mathrm{v}$

Labille, J., Pelinovskaya, N., Botta, C., Bottero, J. Y., and Masion, A. (2012). "Fate of manufactured nanoparticles in aqueous environment," in Encyclopedia of Nanotechnology, ed. B. Bhushan (Dordrecht: Springer), 16.

Labille, J., Slomberg, D., Catalano, R., Robert, S., Apers-Tremelo, M. L., Boudenne, J. L., et al. (2020). Assessing UV filter inputs into beach waters during recreational activity: a field study of three French mediterranean beaches from consumer survey to water analysis. Sci. Total Environ. 706:136010. doi: 10.1016/ j.scitotenv.2019.136010

Lapied, E., Nahmani, J. Y., Moudilou, E., Chaurand, P., Labille, J., Rose, J., et al. (2011). Ecotoxicological effects of an aged $\mathrm{TiO} 2$ nanocomposite measured as apoptosis in the anecic earthworm Lumbricus terrestris after exposure through water, food and soil. Environ. Int. 37:1105. doi: 10.1016/j.envint.2011.01.009

Lazareva, A., and Keller, A. (2014). Estimating potential life cycle releases of engineerednanomaterials from wastewater treatment plants. ACS Sustain. Chem. Eng. 2, 1656-1665. doi: 10.1021/sc500121w

Le Bihan, O., Ounoughene, G., Meunier, L., Debray, B., and Aguerre-Chariol, O. (2017). Incineration of a commercial coating with nano-CeO2. J. Phys. Conf. Ser. 838:012023. doi: 10.1088/1742-6596/838/1/012023

Leroy, D., and Deschamps, P. (1986). Influence of formulation on sunscreen water resistance. Photodermatol. 3, 52-53.

Li, D., Li, B., Wang, Q., Hou, N., Li, C., and Cheng, X. (2016). Toxicity of $\mathrm{TiO} 2$ nanoparticle to denitrifying strain CFY1 and the impact on microbial community structures in activated sludge. Chemosphere 144, 1334-1341. doi: 10.1016/j.chemosphere.2015.10.002

Lindsay, W. L. (1979). The Chemical Equilibria in Soils. Chuchester: Wiley, 449.
Lv, X., Gao, B., Sun, Y., Dong, S., Wu, J., Jiang, B., et al. (2016). Effects of grain size and structural heterogeneity on the transport and retention of nano-TiO2 in saturated porous media. Sci. Total Environ. 563-564, 987-995. doi: 10.1016/ j.scitotenv.2015.12.128

Ma, H., Williams, P. L., and Diamond, S. A. (2013). Ecotoxicity of manufactured $\mathrm{ZnO}$ nanoparticles-a review. Environ. Pollut. 172, 76-85. doi: 10.1016/j.envpol. 2012.08.011

Marques-Santos, L. F., Grassi, G., Bergami, E., Faleri, C., Balbi, T., Salis, A., et al. (2018). Cationic polystyrene nanoparticle and the sea urchin immune system: biocorona formation, cell toxicity, and multixenobiotic resistance phenotype. Nanotoxicology 12, 847-867. doi: 10.1080/17435390.2018.148 2378

Massari, A., Beggio, M., Hreglich, S., Marin, R., and Zuin, S. (2014). Behavior of $\mathrm{TiO}(2)$ nanoparticles during incineration of solid paint waste: a lab-scale test. Waste Manage. 34, 1897-1907. doi: 10.1016/j.wasman.2014.05.015

Matranga, V., Pinsino, A., Celi, M., Di Bella, G., and Natoli, A. (2006). Impacts of UV-B radiation on short-term cultures of sea urchin coelomocytes. Mar. Biol. 149, 25-34. doi: 10.1007/s00227-005-0212-1

Matta, M. K., Florian, J., Zusterzeel, R., Pilli, N. R., Patel, V., Volpe, D.A., et al. (2020). Effect of sunscreen application on plasma concentration of sunscreen active ingredients a randomized clinical trial. JAMA 323, 256-267.

Matta, M. K., Zusterzeel, R., Pilli, N. R., Patel, V., Volpe, D. A., Florian, J., et al. (2019). Effect of sunscreen application under maximal use conditions on plasma concentration of sunscreen active ingredients: a randomized clinical trial. JAMA 321, 2082-2091.

Mesaric, T., Sepcic, K., Drobne, D., Makovec, D., Faimali, M., Morgana, S., et al. (2015). Sperm exposure to carbon-based nanomaterials causes abnormalities in early development of purple sea urchin (Paracentrotus lividus). Aquat. Toxicol. 163, 158-166. doi: 10.1016/j.aquatox.2015.04.012

Migliaccio, O., Pinsino, A., Maffioli, E., Smith, A. M., Agnisola, C., Matranga, V., et al. (2019). Living in future ocean acidification, physiological adaptive responses of the immune system of sea urchins resident at a $\mathrm{CO} 2$ vent system. Sci. Total Environ. 672, 938-950. doi: 10.1016/j.scitotenv.2019.04.005

Mills, A., and Wang, J. (2006). Simultaneous monitoring of the destruction of stearic acid and generation of carbon dioxide by self-cleaning semiconductor photocatalytic films. J. Photochem. Photobiol. A Chem. 182, 181-186. doi: 10.1016/j.jphotochem.2006.02.010

Minetto, D., Libralato, G., and Ghirardini, A. V. (2014). Ecotoxicity of engineered $\mathrm{TiO} 2$ nanoparticles to saltwater organisms: an overview. Environ. Int. 66, 18-27. doi: 10.1016/j.envint.2014.01.012

Mohammed, Y. H., Holmes, A. I, Haridass, N., Sanchez, W. Y., Studier, H., Grice, J. E., et al. (2019). Support for the safe use of zinc oxide nanoparticle sunscreens: lack of skin penetration or cellular toxicity after repeated application in volunteers. J. Invest. Dermatol. 139, 308-315. doi: 10.1016/j.jid.2018. 08.024

Monteiro-Riviere, N. A., Wiench, K., Landsiedel, R., Schulte, S., Inman, A. O., and Riviere, J. E. (2011). Safety evaluation of sunscreen formulations containing titanium dioxide and zinc oxide nanoparticles in UVB sunburned skin: an in vitro and in vivo study. Toxicol. Sci. 123, 264-280. doi: 10.1093/toxsci/kfr148

$\mathrm{Mu}, \mathrm{H} ., \mathrm{Chen}, \mathrm{Y}$. , and Xiao, N. (2011). Effects of metal oxide nanoparticles ( $\mathrm{TiO} 2, \mathrm{Al} 2 \mathrm{O} 3, \mathrm{SiO} 2$ and $\mathrm{ZnO}$ ) on waste activated sludge anaerobic digestion. Bioresour. Technol. 102, 10305-10311. doi: 10.1016/j.biortech.2011.08.100

Mueller, N. C., Buha, J., Wang, J., Ulrich, A., and Nowack, B. (2013). Modeling the flows of engineered nanomaterials during waste handling. Environ. Sci. Process. Impacts 15, 251-259. doi: 10.1039/c2em30761h

OEHHA (2020). California's Proposition 65, in Safe Drinking Water and Toxic Enforcement Act of 1986. Sacramento, CA: California office of environmental health hazard assessment.

Ollivier, P., Pauwels, H., Wille, G., Devau, N., Braibant, G., Cary, L., et al. (2018). Natural attenuation of $\mathrm{TiO} 2$ nanoparticles in a fractured hard-rock. J. Hazard. Mater. 359, 47-55. doi: 10.1016/j.jhazmat.2018.07.035

Osmond, M. J., and McCall, M. J. (2010). Zinc oxide nanoparticles in modern sunscreens: an analysis of potential exposure and hazard. Nanotoxicology 4, 15-41. doi: 10.3109/17435390903502028

Part, F., Berge, N., Baran, P., Stringfellow, A., Sun, W. J., Bartelt-Hunt, S., et al. (2018). A review of the fate of engineered nanomaterials in municipal solid waste streams. Waste Manage. 75, 427-449. doi: 10.1016/j.wasman.2018.02.012 
Petosa, A. R., Brennan, S. J., Rajput, F., and Tufenkji, N. (2012). Transport of two metal oxide nanoparticles in saturated granular porous media: role of water chemistry and particle coating. Water Res. 46, 1273-1285. doi: 10.1016/j.watres. 2011.12.033

Philippe, A., Košík, J., Welle, A., Guigner, J.-M., Clemens, O., and Schaumann, G. E. (2018). Extraction and characterization methods for titanium dioxide nanoparticles from commercialized sunscreens. Environ. Sci. Nano 5, 191-202. doi: 10.1039/c7en00677b

Pinsino, A., and Alijagic, A. (2019). Sea urchin Paracentrotus lividus immune cells in culture: formulation of the appropriate harvesting and culture media and maintenance conditions. Biol. Open 8:bio039289. doi: 10.1242/bio.039289

Pinsino, A., Della Torre, C., Sammarini, V., Bonaventura, R., Amato, E., and Matranga, V. (2008). Sea urchin coelomocytes as a novel cellular biosensor of environmental stress: a field study in the Tremiti Island Marine Protected Area, Southern Adriatic Sea, Italy. Cell Biol. Toxicol. 24, 541-552. doi: 10.1007/ s10565-008-9055-0

Pinsino, A., and Matranga, V. (2015). Sea urchin immune cells as sentinels of environmental stress. Dev. and Comp. Immunol. 49, 198-205. doi: 10.1016/j. dci.2014.11.013

Pinsino, A., Russo, R., Bonaventura, R., Brunelli, A., Marcomini, A., and Matranga, V. (2015). Titanium dioxide nanoparticles stimulate sea urchin immune cell phagocytic activity involving TLR/p38 MAPK-mediated signalling pathway. Sci. Rep. 5:14492.

Poland, C. A., Read, S. A. K., Varet, J., Carse, G., Christensen, F. M., and JHankin, S. M. (2013). Dermal Absorption of Nanomaterials, in Environmental Project No. 1504, 2013. Copenhagen: Danish Ministry of the Environment.

Pradas del Real, A. E., Castillo-Michel, H., Kaegi, R., Larue, C., de Nolf, W., ReyesHerrera, J., et al. (2018). Searching for relevant criteria to distinguish natural vs. anthropogenic TiO2 nanoparticles in soils. Environ. Sci. Nano 5, 2853-2863. doi: $10.1039 /$ c8en00386f

Praetorius, A., Labille, J., Scheringer, M., Thill, A., Hungerbuhler, K., and Bottero, J. Y. (2014). Heteroaggregation of titanium dioxide nanoparticles with model natural colloids under environmentally relevant conditions. Environ. Sci. Technol. 48, 10690-10698. doi: 10.1021/es501655v

Reed, R. B., Martin, D. P., Bednar, A. J., Montano, M. D., Westerhoff, P., and Ranville, J. F. (2017). Multi-day diurnal measurements of Ti-containing nanoparticle and organic sunscreen chemical release during recreational use of a natural surface water. Environ. Sci. Nano 4, 69-77. doi: 10.1039/c6en $00283 \mathrm{~h}$

Risk and Policy Analysts Limited (2004). Comparative Study on Cosmetics Legislation in the EU and Other Principal Markets with Special Attention to So-Called Borderline Products. Norfolk: Risk \& Policy Analysts Limited.

Rodriguez-Romero, A., Ruiz-Gutierrez, G., Viguri, J., and Tovar-Sanchez, A. (2019). Sunscreens as a new source of metals and nutrients to coastal waters. Environ. Sci. Technol. 53, 10177-10187. doi: 10.1021/acs.est.9b02739

Rossano, M., Hucher, N., Picard, C., Colletta, D., Le Foll, F., and Grisel, M. (2014). Effects of aging on structure and stability of TiO2 nanoparticle-containing oilin-water emulsions. Int. J. Pharm. 461, 89-96. doi: 10.1016/j.ijpharm.2013. 11.039

Rowenczyk, L., Duclairoir-Poc, C., Barreau, M., Picard, C., Hucher, N., Orange, N., et al. (2017). Impact of coated $\mathrm{TiO} 2$-nanoparticles used in sunscreens on two representative strains of the human microbiota: effect of the particle surface nature and aging. Colloid. Surf. B Biointerf. 158, 339-348. doi: 10.1016/j. colsurfb.2017.07.013

Sanchez-Quiles, D., and Tovar-Sanchez, A. (2014). Sunscreens as a source of hydrogen peroxide production in coastal waters. Environ. Sci. Technol. 48, 9037-9042. doi: 10.1021/es5020696

Sani-Kast, N., Scheringer, M., Slomberg, D., Labille, J., Praetorius, A., Ollivier, P., et al. (2015). Addressing the complexity of water chemistry in environmental fate modeling for engineered nanoparticles. Sci. Total Environ. 535, 150-159. doi: 10.1016/j.scitotenv.2014.12.025

Santaella, C., Allainmat, B., Simonet, F., Chaneac, C., Labille, J., Auffan, M., et al. (2014). Aged TiO2-based nanocomposite used in sunscreens produces singlet oxygen under long-wave UV and sensitizes Escherichia coli to Cadmium. Environ. Sci. Technol. 48, 5245-5253. doi: 10.1021/es500216t

Santos, A. S. F., Teixeira, B. A. N., Agnelli, J. A. M., and Manrich, S. (2005). Characterization of effluents through a typical plastic recycling process: an evaluation of cleaning performance and environmental pollution. Resour. Conserv. Recycl. 45, 159-171. doi: 10.1016/j.resconrec.2005.01.011
SCCS (2012). OPINION ON Zinc oxide (Nano Form) COLIPA S 76. Brussels: Scientific Committee on Consumer Safety.

SCCS (2014). OPINION ON Titanium Dioxide (Nano Form) COLIPA S75. Brussels: Scientific Committee on Consumer Safety.

Schlumpf, M., Schmid, P., Durrer, S., Conscience, M., Maerkel, K., Henseler, M., et al. (2004). Endocrine activity and developmental toxicity of cosmetic UV filters - an update. Toxicology 205, 113-122. doi: 10.1016/j.tox.2004.06.043

Schneider, S. L., and Lim, H. W. (2019). A review of inorganic UV filters zinc oxide and titanium dioxide. Photodermatol. Photoimmunol. Photomed. 35, 442-446. doi: $10.1111 /$ phpp. 12439

Schulz, J., Hohenberg, H., Pflucker, F., Gartner, E., Will, T., Pfeiffer, S., et al. (2002). Distribution of sunscreens on skin. Adv. Drug Deliv. Rev. 54, S157-S163.

Semenzato, A., Dall'aglio, C., Boscarini, G. M., Ongaro, A., Bettero, A., Sangalli, M. E., et al. (1994). Chemico-physical and functional properties of inorganic sunscreens in cosmetic products. Int. J. Cosmet. Sci. 16, 247-255. doi: 10.1111/ j.1467-2494.1994.tb00101.x

Sendra, M., Sanchez-Quiles, D., Blasco, J., Moreno-Garrido, I., Lubian, L. M., Perez-Garcia, S., et al. (2017). Effects of $\mathrm{TiO} 2$ nanoparticles and sunscreens on coastal marine microalgae: ultraviolet radiation is key variable for toxicity assessment. Environ. Int. 98, 62-68. doi: 10.1016/j.envint.2016. 09.024

Shao, Y., and Schlossman, D. (1999). Effect of Particle Size on Performance of Physical Sunscreen Formulas. Shanghai: PCIA Conference.

Simonet, B. M., and Valcarcel, M. (2009). Monitoring nanoparticles in the environment. Anal. Bioanal. Chem. 393, 17-21. doi: 10.1007/s00216-0082484-Z

Slomberg, D., Catalano, R., Ziarelli, F., Viel, S., Bartolomei, V., Labille, J., et al. (2020). Aqueous aging of a silica coated TiO2 UV filter used in sunscreens: investigations at the molecular scale with dynamic nuclear polarization NMR. RSC Adv. 10, 8266-8274. doi: 10.1039/d0ra00595a

Smijs, T. G., and Pavel, S. (2011). Titanium dioxide and zinc oxide nanoparticles in sunscreens: focus on their safety and effectiveness. Nanotechnol. Sci. Appl. 4, 95-112.

Smith, L. C., Arizza, V., Hudgell, M. A. B., Barone, G., Bodnar, A. G., Buckley, K. M., et al. (2008). "Echinodermata: the complex immune system in echinoderms," in Advances in Comparative Immunology, ed. E. L. Cooper (Cham: Springer International Publishing), 409-501.

Solovitch, N., Labille, J., Rose, J., Chaurand, P., Borschneck, D., Wiesner, M. R., et al. (2010). Concurrent aggregation and deposition of $\mathrm{TiO} 2$ nanoparticles in a sandy porous media. Environ. Sci. Technol. 44, 4897-4902. doi: 10.1021/ es1000819

Sposito, G. (2008). The Chemistry of Soils, 2nd Edn. Oxford: Oxford University Press, 329.

Steinberg, D. (2007). Global regulations of sunscreens. Int. J. Cosmet. Sci. 29, 409-411.

Sun, T. Y., Gottschalk, F., Hungerbuhler, K., and Nowack, B. (2014). Comprehensive probabilistic modelling of environmental emissions of engineered nanomaterials. Environ. Pollut. 185, 69-76. doi: 10.1016/j.envpol. 2013.10.004

Tharaud, M., Gondikas, A. P., Benedetti, M. F., von der Kammer, F., Hofmann, T., and Cornelis, G. (2017). TiO2 nanomaterial detection in calcium rich matrices by spICPMS. A matter of resolution and treatment. J. Anal. Atomic Spectr. 32, 1400-1411. doi: 10.1039/c7ja00060j

Topuz, E., Traber, J., Sigg, L., and Talinli, I. (2015). Agglomeration of Ag and TiO2 nanoparticles in surface and wastewater: role of calcium ions and of organic carbon fractions. Environ. Pollut. 204, 313-323. doi: 10.1016/j.envpol.2015. 05.034

Tovar-Sanchez, A., Sanchez-Quiles, D., Basterretxea, G., Benede, J. L., Chisvert, A. Salvador, A., et al. (2013). Sunscreen products as emerging pollutants to coastal waters. PLoS One 8:e65451. doi: 10.1371/journal.pone.0065451

Tovar-Sanchez, A., Sanchez-Quiles, D., and Rodriguez-Romero, A. (2019). Massive coastal tourism influx to the Mediterranean Sea: the environmental risk of sunscreens. Sci. Total Environ. 656, 316-321. doi: 10.1016/j.scitotenv.2018. 11.399

Turkoglu, M., and Yener, S. (1997). Design and in vivo evaluation of ultrafine inorganic-oxide-containing-sunscreen formulations. Int. J. Cosmet. Sci. 19, 193-201. doi: 10.1046/j.1467-2494.1997.171714.x

Tyner, K. M., Wokovich, A. M., Godar, D. E., Doub, W. H., and Sadrieh, N. (2011). The state of nano-sized titanium dioxide (TiO2) may affect sunscreen 
performance. Int. J. Cosmet. Sci. 33, 234-244. doi: 10.1111/j.1468-2494.2010. 00622.x

U.S. EPA (2010). Nanomaterial Case Studies: Nanoscale Titanium Dioxide in Water Treatment and in Topical Sunscreen. Washington, DC: U.S. Environmental Protection Agency, 204.

UNEP (2009). Sustainable Coastal Tourism: An Integrated Planning and Management Approach. Nairobi: United Nations Environment Programme.

Venkatesan, A. K., Reed, R. B., Lee, S., Bi, X., Hanigan, D., Yang, Y., et al. (2018). Detection and sizing of Ti-containing particles in recreational waters using single particle ICP-MS. Bull. Environ. Contaminat. Toxicol. 100, 120-126. doi: 10.1007/s00128-017-0862216-1

Virkutyte, J., Al-Abed, S. R., and Dionysiou, D. D. (2012). Depletion of the protective aluminum hydroxide coating in TiO2-based sunscreens by swimming pool water ingredients. Chem. Eng. J. 191, 95-103. doi: 10.1016/j. cej.2012.02.074

Wakefield, G., Lipscomb, S., Holland, E., and Knowland, J. (2004). The effects of manganese doping on UVA absorption and free radical generation of micronised titanium dioxide and its consequences for the photostability of UVA absorbing organic sunscreen components. Photochem. Photobiol. Sci. 3, 648-652.

Yung, M. M. N., Fougeres, P. A., Leung, Y. H., Liu, F., Djurisic, A. B., Giesy, J. P., et al. (2017). Physicochemical characteristics and toxicity of surface-modified zinc oxide nanoparticles to freshwater and marine microalgae. Sci. Rep 7:15909.

Zhang, M., Yang, J. H., Cai, Z. X., Feng, Y. D., Wang, Y. F., Zhang, D. Y., et al. (2019). Detection of engineered nanoparticles in aquatic environments: current status and challenges in enrichment, separation, and analysis. Environ. Sci. Nano 6, 709-735. doi: 10.1039/c8en01086b

Zheng, X., Chen, Y., and Wu, R. (2011). Long-term effects of titanium dioxide nanoparticles on nitrogen and phosphorus removal from wastewater and bacterial community shift in activated sludge. Environ. Sci. Technol. 45, 72847290. doi: $10.1021 /$ es2008598

Conflict of Interest: The authors declare that the research was conducted in the absence of any commercial or financial relationships that could be construed as a potential conflict of interest.

Copyright (c) 2020 Labille, Catalano, Slomberg, Motellier, Pinsino, Hennebert, Santaella and Bartolomei. This is an open-access article distributed under the terms of the Creative Commons Attribution License (CC BY). The use, distribution or reproduction in other forums is permitted, provided the original author(s) and the copyright owner(s) are credited and that the original publication in this journal is cited, in accordance with accepted academic practice. No use, distribution or reproduction is permitted which does not comply with these terms. 